University of Rhode Island

DigitalCommons@URI

Open Access Master's Theses

1995

\title{
THE EFFECTS OF METHYLENE BLUE PRETREATMENT ON GLOBAL ISCHEMIA IN THE ISOLATED RAT HEART
}

Stephen Robert Gorman

University of Rhode Island

Follow this and additional works at: https://digitalcommons.uri.edu/theses

\section{Recommended Citation}

Gorman, Stephen Robert, "THE EFFECTS OF METHYLENE BLUE PRETREATMENT ON GLOBAL ISCHEMIA IN THE ISOLATED RAT HEART" (1995). Open Access Master's Theses. Paper 253.

https://digitalcommons.uri.edu/theses/253

This Thesis is brought to you for free and open access by DigitalCommons@URI. It has been accepted for inclusion in Open Access Master's Theses by an authorized administrator of DigitalCommons@URI. For more information, please contact digitalcommons-group@uri.edu. 


\title{
THE EFFECTS OF METHYLENE BLUE PRETREATMENT ON GLOBAL ISCHEMIA IN THE ISOLATED RAT HEART \\ BY STEPHEN ROBERT GORMAN
}

\begin{abstract}
A THESIS SUBMITTED IN PARTIAL FULFILLMENT OF THE REQUIREMENTS FOR THE DEGREE OF MASTER OF SCIENCE
\end{abstract}

IN PHARMACOLOGY AND TOXICOLOGY 


\section{MASTER OF SCIENCE THESIS}

OF

STEPHEN ROBERT GORMAN

\section{APPROVED:}

Thesis Committee
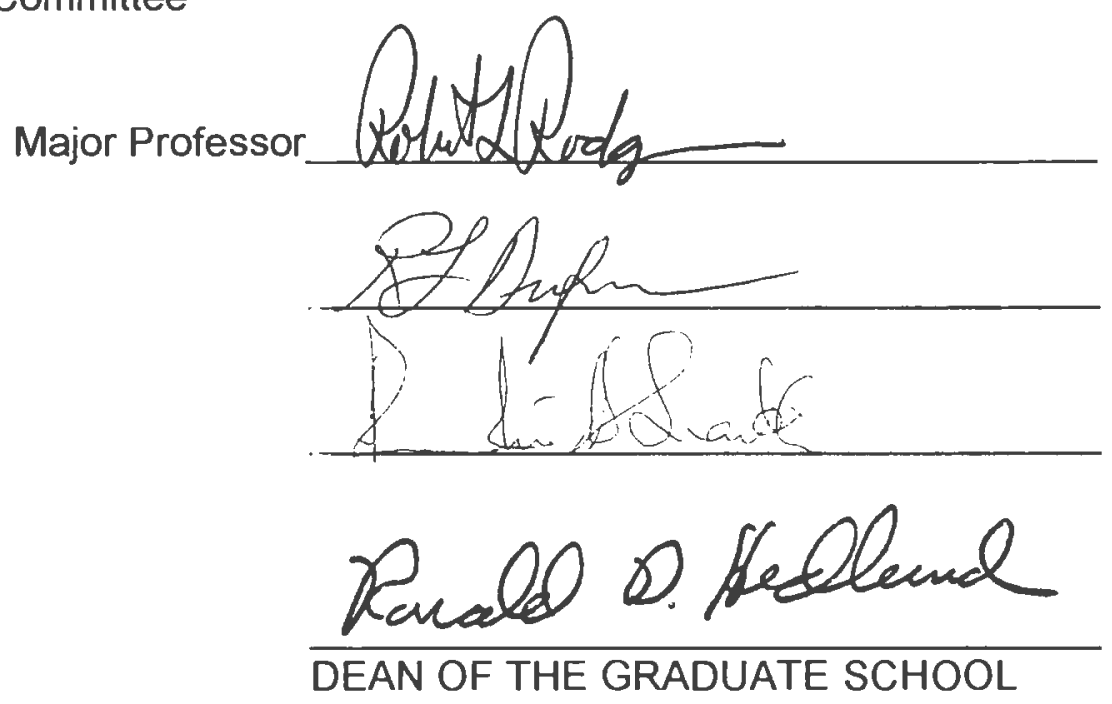

UNIVERSITY OF RHODE ISLAND 


\section{THESIS ABSTRACT}

The phenomena of cardiac ischemia and reperfusion involve substantial, multifactorial pathophysiologic derangements, the attenuation of which is vital for the functional recovery and viability of the heart. It has been proposed that methylene blue (MB) may decrease the damage associated with ischemia and reperfusion, in part by the suppression of oxyradical generation and by the enhancement of ATP recovery. In the present study, we tested the effect of pretreating isolated working rat hearts with MB prior to imposing ischemia and reperfusion. Hearts were treated for ten minutes with either $0.1 \mu \mathrm{M}, 1.0 \mu \mathrm{M}$, or $10.0 \mu \mathrm{M} \mathrm{MB}$, or given no treatment, prior to thirty-five minutes of zero flow, global ischemia and ten minutes of subsequent reperfusion. The mechanical performance and electrical activity of the hearts were monitored throughout the experiments. In addition, aliquots of coronary artery effluent were periodically collected for biochemical analyses. The cardiac tissue was frozen at the end of the experiments and subsequently assayed to estimate the extent of membrane phospholipid peroxidation. The incidence and duration of ventricular fibrillation occurring during reperfusion in the MB-treated hearts were not significantly different from the untreated hearts. The measurement of coronary artery flow during reperfusion was similar in both untreated and treated groups. The appearance of lactate dehydrogenase in the coronary artery effluent of treated hearts approximated those levels measured in untreated hearts. The calculated indices of electromechanical recovery did not differ significantly from the value 
obtained for the untreated pool. There were comparable levels of thiobarbituric acid reactive substances (TBARS) detected in the cardiac tissue from treated and untreated groups. Since MB did not exhibit significant protective effects during ischemia and reperfusion, we also conducted an experiment with $100 \mathrm{nM}$ erythro-9-(2-hydroxy-3-nonyl)adenine (EHNA), an adenosine deaminase inhibitor. Previous studies with EHNA pretreatment in our laboratory have demonstrated measurable cardioprotection, however this observation was not reproduced in the present study. In summary, we did not observe cardioprotective effects using several concentrations of MB in our isolated working rat heart model of global ischemia/reperfusion injury. 


\section{ACKNOWLEDGMENTS}

My appreciation is extended to Robert L. Rodgers, Ph.D., Professor of Pharmacology, for his expertise and direction throughout the course of this study. In addition, my sincere thanks is conveyed to my thesis committee members, Dr. John Babson, Dr. Robert Dufresne, and Dr. Zahir Shaikh for their time, advice, and technical assistance.

To my student colleagues, Krista Bolduc, Thomas Daniels, Swapnil Raut, Supti Sarkhar, and Amanda Vu, whose words of friendship and encouragement helped me to visualize the completion of this project, I thank you and wish all of you much success in your endeavors.

To Eleanor Gray and Jane Northup, who went beyond the call of their duties to assist me, your deeds are fondly remembered.

To my family, especially my parents, who stood by me with faith, hope, and love as I pursued my goals and navigated the sometimes difficult course to the next phase of my life, I could not have accomplished my goals without your support. 


\section{PREFACE}

This thesis was prepared in the manuscript format. The manuscript entitled "The Effects of Methylene Blue Pretreatment on Global Cardiac Ischemia in the Isolated Rat Heart" was written according to the "Instructions to Authors" for the Canadian Journal of Physiology and Pharmacology. 


\section{TABLE OF CONTENTS}

\section{Page}

THESIS ABSTRACT

ACKNOWLEDGMENTS

iv

PREFACE

V

TABLE OF CONTENTS

vi

LIST OF TABLES

vii

LIST OF FIGURES

viii

MANUSCRIPT: THE EFFECTS OF METHYLENE BLUE PRE-

TREATMENT ON GLOBAL ISCHEMIA IN THE ISOLATED RAT HEART

TITLE PAGE

ABSTRACT

INTRODUCTION

METHODS

RESULTS

9

TABLES

FIGURES

DISCUSSION

LIST OF REFERENCES

APPENDIX A: INTRODUCTION AND LITERATURE REVIEW OF THE PROBLEM

APPENDIX B: SUMMARY OF RAW DATA AND STATISTICAL ANALYSES 


\section{LIST OF TABLES}

Manuscript

Page

Table 1. Effect of Methylene Blue on the Duration and Incidence of Ventricular Fibrillation during Reperfusion

Appendix B

Table 2. A Summary of Raw Data for the Duration and Incidence of Ventricular Fibrillation during Reperfusion

Table 3. A Summary of Calculated Indices of Electromechanical Recovery

Table 4a. A Summary of the Levels of TBARS in Frozen Cardiac Tissue (Untreated)

Table 4b. A Summary of the Levels of TBARS in Frozen Cardiac Tissue (Treated)

Table 5a. Coronary Artery Flow Rates (Untreated)

Table 5b. Coronary Artery Flow Rates (Treated)

Table 6a. Lactate Dehydrogenase Activity in Coronary Artery Effluent (Untreated)

Table 6b. Lactate Dehydrogenase Activity in Coronary Artery Effluent (Treated)

Table 7. Summary of Results with EHNA [100nm] 


\section{LIST OF FIGURES}

Manuscript

Page

Figure 1. Effect of methylene blue on coronary artery flow during reperfusion

Figure 2. Effect of methylene blue on the appearance of lactate dehydrogenase in coronary artery effluent during reperfusion

Figure 3. Effect of methylene blue on the calculated index of electromechanical recovery (Ir)

Figure 4. Effect of methylene blue pretreatment on the formation of thiobarbituric acid reactive substances (TBARS) 
Manuscript: The Effects of Methylene Blue Pretreatment on Global Ischemia in The Isolated Rat Heart 


\begin{abstract}
It has been proposed that methylene blue (MB) might protect the myocardium against ischemia/reperfusion damage in part by suppression of oxyradical generation and by enhancement of high energy phosphate synthesis. In the present study, we tested the effect of pretreatment with MB on ischemia and reperfusion injury in the isolated working rat heart. In the experimental groups, hearts were treated for ten minutes with either $0.1 \mu \mathrm{M}, 1.0 \mu \mathrm{M}$, or 10.0 $\mu \mathrm{M}$ methylene blue prior to thirty-five minutes of zero flow, global ischemia and ten minutes of subsequent reperfusion. The incidence and duration of ventricular fibrillation occurring during reperfusion were not significantly different from the untreated hearts. The measurement of coronary artery flow during reperfusion was similar for both the untreated and treated groups. The appearance of lactate dehydrogenase, an indicator of cellular damage, in the coronary artery effluent of treated hearts approximated those levels measured in the untreated hearts. Similarly, the calculated mean indices of electromechanical recovery did not differ significantly between the treated and untreated groups. Also, the index of lipid peroxidative injury, levels of thiobarbituric acid reactive substances (TBARS) in assayed frozen cardiac tissue, were comparable in both the treated and untreated groups. These results demonstrate that $\mathrm{MB}$ did not attenuate the damage associated with ischemia and reperfusion in our isolated rat heart model.
\end{abstract}




\section{INTRODUCTION}

It has been well-established that ischemia occurs when quantities of substrate and oxygen are insufficient to meet the metabolic and energy demands of myocardial tissue (Jennings and Reimer, 1991). During the ischemic period, a constellation of metabolic, structural, and functional derangements arise, the severity of which depend on the extent and duration of coronary artery flow compromise (Downey, 1990). The manifestations of myocardial ischemia have been well-defined. They include a rapid impairment in contractile performance, depletion of high energy phosphate stores and an increase in intracellular inorganic phosphate, dependency on anaerobic metabolism leading to a buildup of glycolytic byproducts, intracellular acidosis as a result of proton and lactate accumulation, and arrhythmogenesis precipitated by hyperkalemia secondary to the failure of membranous $\mathrm{Na}^{+}-\mathrm{K}^{+}-\mathrm{ATPase}$ pumps. Prolonged ischemia culminates in tissue necrosis and infarction (Jennings and Reimer, 1991; Karmazyn, 1991; Katz, 1992).

Timely reperfusion of ischemic myocardium, though absolutely essential for its salvage, is paradoxically associated with deleterious sequelae and exacerbation of tissue damage. The phenomenon of reperfusion injury is characterized by several pathophysiologic derangements, including the induction of lethal ventricular arrhythmias, prolonged depression of contractile function, major ultrastructural damage, and massive leakage of cytosolic enzymes (Korthuis and Granger, 1993). The mechanisms underlying the 
pathogenesis of reoxygenation injury have not been fully elucidated, but the etiology is multifactorial and involves a concerted series of events (Karmazyn, 1990). Free radical-mediated oxidative damage (Bolli, 1991; Goldhaber and Weiss, 1992) and an irreversible collapse of intracellular ionic homeostasis (Darley-Usmar et al., 1991) have been implicated as major contributors to the pathologic process. Numerous laboratories have investigated possible interventions, but none has demonstrated significant clinical utility.

Mahoney (1990) postulated that the commonly used tissue dye, methylene blue (MB), which oxidizes $\mathrm{NADPH}$ to $\mathrm{NADPH}^{+}$, increases flux through the hexosemonophosphate shunt and thereby hastens ATP synthesis for improved electromechanical recovery and function of the heart following ischemia and reperfusion. Normally, during ischemia-induced catabolism of adenine nucelotides, electrons are routed to the flavin site on xanthine oxidase for the reduction of molecular oxygen and subsequent formation of superoxide radicals. Salaris (1991) proposed that MB may prevent the formation of cytotoxic oxygen radical species by parasitically accepting electrons from xanthine oxidase. Other laboratories have also reported that MB may block oxygen radical generation in reperfusion injury by decreasing superoxide production in vitro [Kelner et al., 1988a and 1988b]. Our search of the literature revealed no studies employing $\mathrm{MB}$ as a potential therapeutic agent in animal models of ischemia and reperfusion. We hypothesized that treatment with MB prior to ischemia and reperfusion would attenuate myocardial tissue damage by 
assuring its immediate availability for action by the aforementioned mechanisms in cells presented with a metabolic challenge. We also hypothesized that cardioprotection would be observed by a marked improvement in electrical and mechanical recovery during reperfusion, decreased cytosolic enzyme leakage, and decreased levels of membrane lipid peroxidative injury. In the present study, we administered MB at several concentrations prior to the imposition of ischemia and subsequent reperfusion in isolated working rat hearts. 


\section{METHODS}

\section{Heart Perfusion}

Male Sprague Dawley rats weighing $300-400 \mathrm{~g}$ were fed ad libitum and cared for in accordance with institutional guidelines and procedures. Animals were injected i.p. with heparin (1000 U/kg body weight) ten minutes prior to sacrifice. The hearts were rapidly excised, and the aortas were isolated and mounted on a $14 \mathrm{~g}$ cannula. Perfusion was initially performed in the Langendorff mode for 3-5 minutes. The perfusate was a modified, non-recirculating KrebsHenseleit buffer containing the following: $\mathrm{NaCl}(120 \mathrm{mM}), \mathrm{KCl}(5.6 \mathrm{mM}), \mathrm{MgSO}_{4}$ (0.65 mM), $\mathrm{CaCl}_{2}(2.4 \mathrm{mM}), \mathrm{NaH}_{2} \mathrm{PO}_{4}(1.21 \mathrm{mM}), \mathrm{EDTA}(0.2 \mathrm{mM}), \mathrm{NaHCO}_{3}(20$ $\mathrm{mM}$ ); gassed with $95 \% \mathrm{O}_{2}$ and $5 \% \mathrm{CO}_{2} ; \mathrm{pH} 7.4$. The left atrium was cannulated to allow for perfusate inflow. Left atrial filling pressure was set at $10 \mathrm{~cm} \mathrm{H}_{2} \mathrm{O}$. The pulmonary artery was cannulated to allow for the collection and measurement of coronary artery effluent, and the heart was subsequently switched to the working mode. The hearts were allowed to stabilize for ten minutes prior to drug treatment or data collection. The perfusion apparatus was enclosed in a thermostatic chamber at $37^{\circ} \mathrm{C}$. MB was continuously infused for ten minutes into the left atrial filling reservoir via a syringe pump prior to the ischemic period of thirty-five minutes and a subsequent reperfusion period of ten minutes. Global cardiac ischemia and reperfusion were achieved by closing and opening, respectively, of both the aortic and left atrial perfusion lines. At the end of experiments hearts were freeze-clamped in liquid nitrogen and were 
transferred to $\mathrm{a}-80^{\circ} \mathrm{C}$ freezer for subsequent biochemical analysis.

\section{Pressure and Flow Measurements}

Left ventricular pressure development (LVP) was monitored and recorded continually on a Model 7 polygraph unit (Grass Instrument Co.) linked to a pressure transducer. The transducer was attached to a $3 \mathrm{~cm}$ piece of PE90 tubing, which was inserted into the left ventricle through the pulmonary vein and pulled out through the apex of the heart leaving one end of the cannula in the left ventricular chamber. Electrocardiographic rhythm (ECG) was monitored and recorded through electrodes that were placed in both atria and in the left ventricle. Heart rate $(\mathrm{HR})$ and the presence of ventricular fibrillation were determined from the ECG. Coronary flow rate (CF) was assessed by weighing coronary effluent collected over one minute intervals.

\section{Assay of Lactate Dehydrogenase Activity}

Samples of coronary effluent were analyzed for lactate dehydrogenase (LDH). The assay contained the following (in final concentrations): $0.2 \mathrm{M}$ Tris$\mathrm{HCl}$ buffer, $\mathrm{pH} 7.3 ; 1.0 \mathrm{mM}$ pyruvate; $0.22 \mathrm{mM} \mathrm{NADH}$. The LDH activity was measured at $30^{\circ} \mathrm{C}$ as the amount of pyruvate consumed by monitoring the rate of decrease of absorbance due to the oxidation of the coenzyme, NADH. Absorbance was measured at $340 \mathrm{~nm}$ with a Beckman DU-64 spectrophotometer. LDH activity is expressed in units where $1 \mathrm{U}$ is that which oxidizes $1 \mu \mathrm{mol} \mathrm{NADH} /$ minute. 


\section{Assay of Thiobarbituric Acid Reactive Substances}

Lipid peroxidation was assessed by determining the content of thiobarbituric acid reactive substances (TBARS) in $200 \mathrm{mg}$ aliquots of freezeclamped heart muscle which were mixed with $20 \%$ trichloroacetic acid and centrifugated at $1000 \times \mathrm{g}$ for 20 minutes. $1 \mathrm{~mL}$ of the supernatant was reacted with $100 \mathrm{mM}$ thiobarbituric acid, capped, and heated in a $95^{\circ} \mathrm{C}$ heating block for 20 minutes. After cooling for ten minutes, TBARS were quantitated at $532 \mathrm{nM}$ using 1,1,3,3-tetraethoxypropan (Aldrich) as standard.

\section{Statistical Analysis}

Comparisons between untreated and treated groups for the measurements of lactate dehydrogenase activity and coronary artery flow at several timepoints during reperfusion were made by a multifactorial analysis of variance (ANOVA) with repeated measures. Analyses of ventricular fibrillation incidence and duration, levels of TBARS, and indices of electromechanical recovery were done using two-way analysis of variance (ANOVA) with a Dunnett's follow-up test. The level of significance was set at $p<0.05$. All statistical computations were done using SYSTAT ${ }^{\circledR}$. 


\section{RESULTS}

In hearts subjected to ischemia and reperfusion without prior treatment, the mean incidence of ventricular fibrillation occurring during reperfusion was $68.8 \%$. The duration of ventricular fibrillation averaged 6.29 minutes (Table 1). The the lowest concentration of MB tested in this study was observed to produce a mean duration of ventricular tachyarrhythmias longer than that observed in the untreated group and resulted in a $100 \%$ incidence of ventricular fibrillation.

Statistically, however, these observations were not significant.

The normalized mean coronary flow rates during preischemia among the various groups ranged between 4.15 and $7.88 \mathrm{~mL} /$ minute $\times \mathrm{g}$ wet heart weight. During the reperfusion period, MB produced no significant difference in the coronary flow rates (Figure 1).

The measurements of lactate dehydrogenase (LDH) activity in coronary artery effluent prior to ischemia and during reperfusion were comparable between MB-treated and untreated groups (Figure 2).

The calculated index of electromechanical recovery (Ir) is an unweighted formula incorporating ventricular fibrillation duration (VFD), heart rate (HR), and left ventricular pulse pressure $(\mathrm{LVPP})$, such that Ir $=\left[\left(\mathrm{LVPP}_{\text {final }} / \mathrm{LVPP}_{\text {intial }}\right)+\right.$ $\left.\left(H R_{\text {final }} / H R_{\text {initial }}\right)+((10-V F D) / 10)\right] / 3$. By including these three parameters of electrical and mechanical performance, this calculation allows comparisons to be made based on the overall functional recovery of the hearts at the end of each experiment. The Ir's determined for all concentrations of MB tested in this 
study were not significantly different from the ir calculated for the untreated hearts (Figure 3).

Membrane lipid peroxidative injury in the untreated, ischemic/reperfused hearts was quantified as having a mean of 22.69 nmoles TBARS/g tissue. MB did not reduce the levels of TBARS in myocardial tissue frozen at the end of reperfusion and assayed six weeks later (Figure 4). 
Table 1. Effect of methylene blue on the duration and incidence of ventricular fibrillation during reperfusion. 


\section{Duration (minutes)}

Incidence (\%)

Untreated

$6.29 \pm 4.78$

68.8

Methylene blue $0.1 \mu \mathrm{M}$

$9.78 \pm 0.67$

100

Methylene blue $1.0 \mu \mathrm{M}$

$4.28 \pm 4.63$

55.5

Methylene blue $10.0 \mu \mathrm{M}$

$6.44 \pm 4.85$

66.6

Values for the duration of ventricular fibrillation occurring during the ten minutes of reperfusion are expressed as mean $\pm S D$. The incidence is the mean percent occurrence of $\geq 1$ minute of ventricular fibrillation during reperfusion. Sample size is 9 for all groups except the untreated $(n=32)$. 
Figure 1. Effect of methylene blue on coronary artery flow during reperfusion. Samples of effluent were collected over one minute intervals preceding the designated time point. Minutes 0-10 are preischemia. Minutes 45-55 are postischemia. Each point represents the mean \pm SD. Sample size is 9 for all groups except the untreated $(n=32)$. 


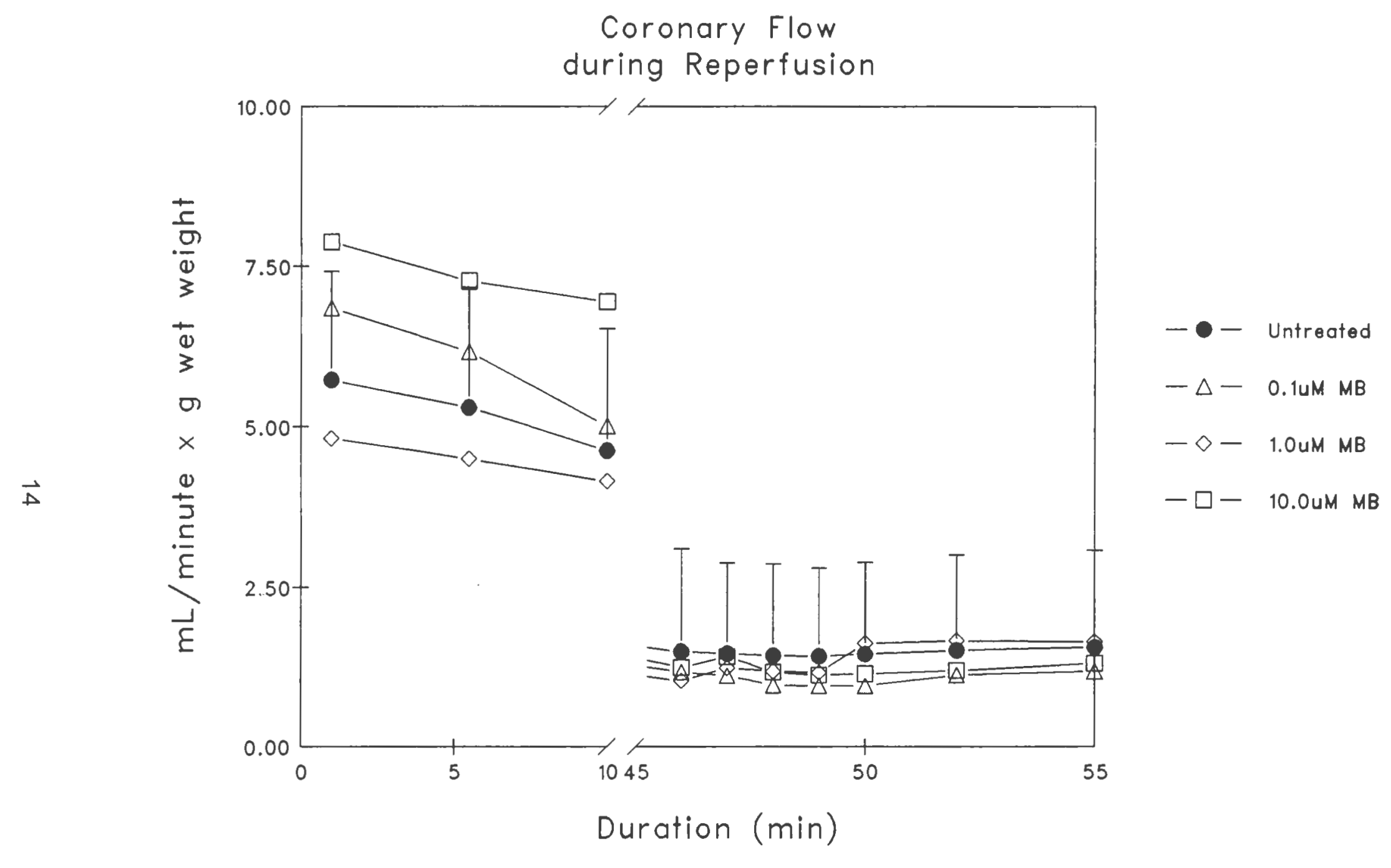


Figure 2. Effect of methylene blue on the appearance of LDH in the coronary artery effluent during reperfusion. Samples of effluent were collected over one minute intervals preceding the designated time point. Minutes 0-10 are preischemia. Minutes 45-55 are postischemia. Each point represents the mean \pm SD. Sample size is 9 for all groups except the untreated $(n=32)$. 
Lactate Dehydrogenase Leakage into Coronary Artery Effluent

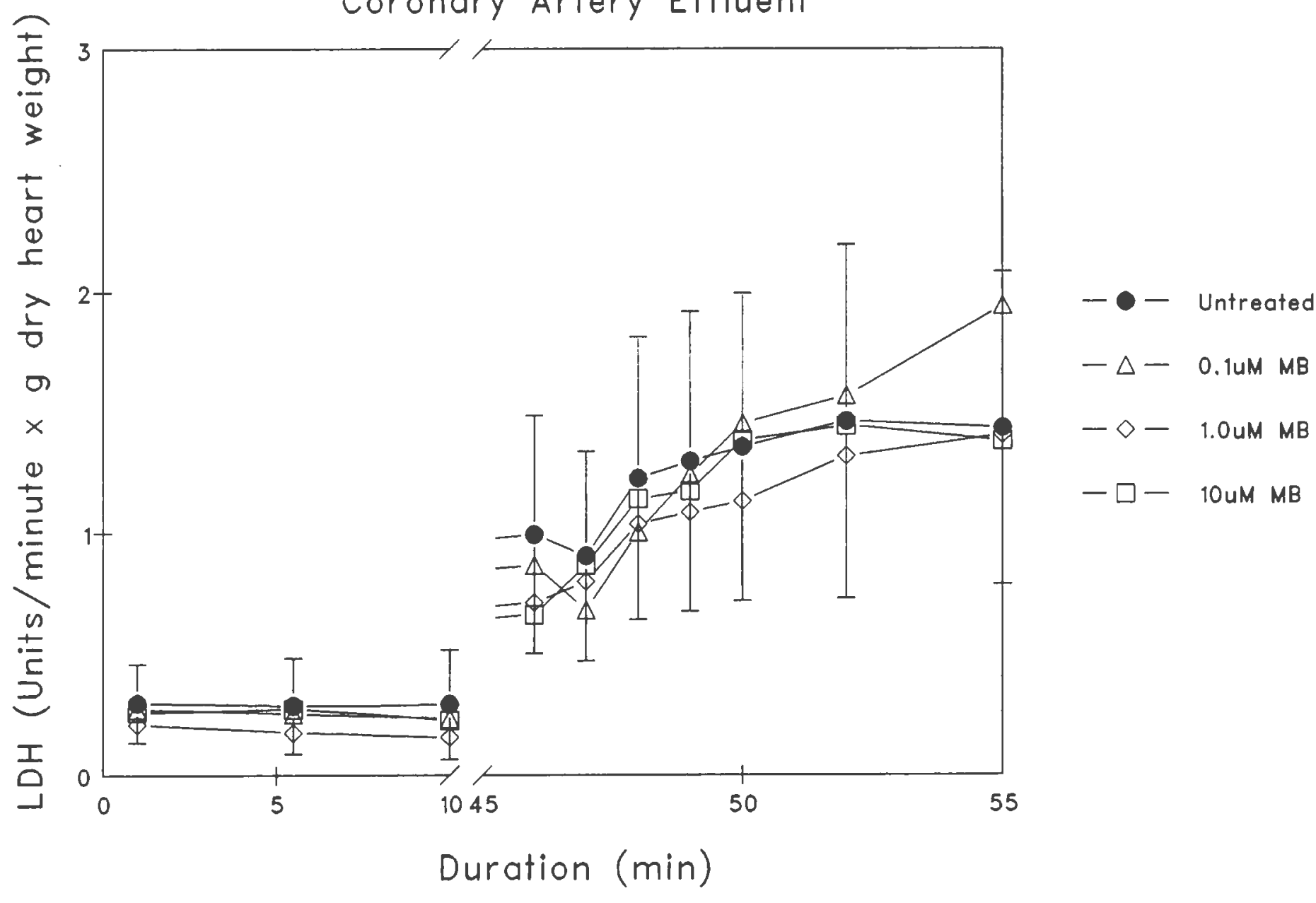


Figure 3. Effect of methylene blue on the calculated index of electromechanical recovery (Ir). Each point represents the mean \pm SD. Sample size is 9 for all groups except the untreated $(n=32)$. 
Index of Electromechanical Recovery (Ir) at the Endpoint of Reperfusion

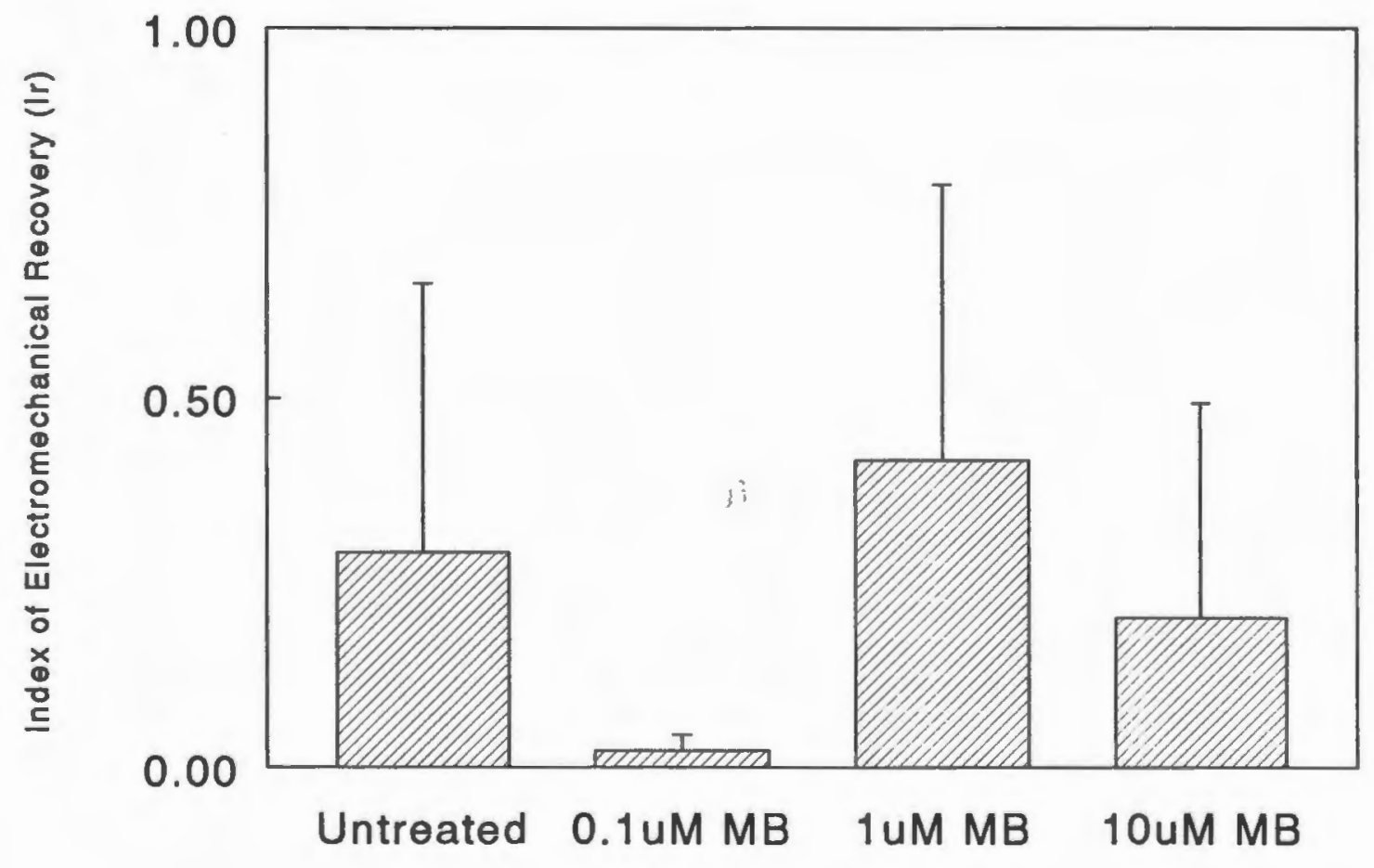


Figure 4. Effect of methylene blue pretreatment on the formation of thiobarbituric acid reactive substances (TBARS) as determined in homogenates of cardiac tissue. Hearts were freeze-clamped in liquid nitrogen at the endpoint of reperfusion and subsequently assayed. Each bar represents the mean \pm SD. Sample size is 9 for all groups except the untreated $(n=32)$. 
TBARS in Frozen Cardiac Tissue at the Endpoint of Reperfusion

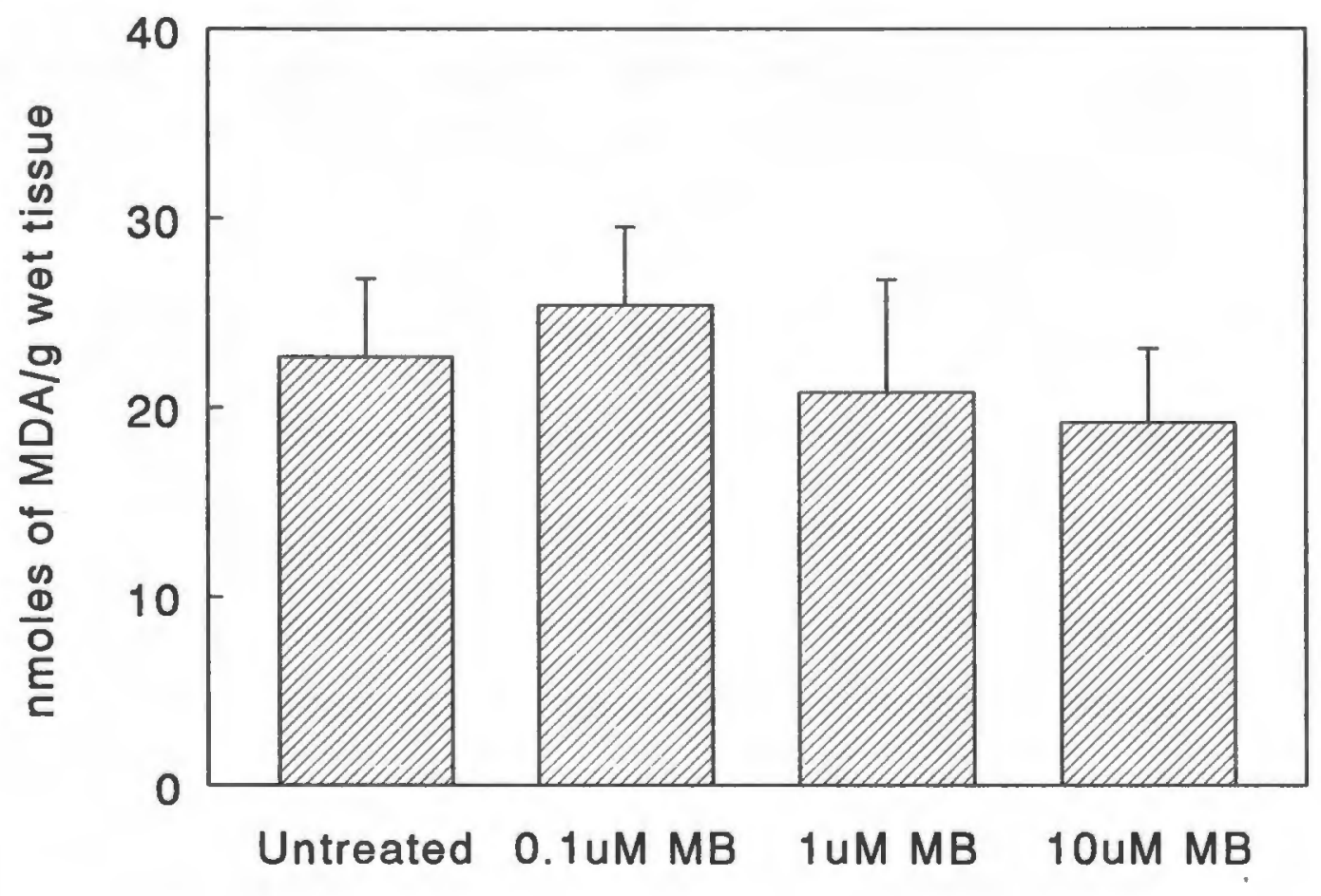




\section{DISCUSSION}

In the present study, MB did not offer significant protection from the damaging effects of global cardiac ischemia and reperfusion. Our hypothesis, that MB would minimize the damage involved in ischemia and reperfusion if administered prior to the ischemic insult, was not supported by the data.

It has been reported that MB may attenuate ischemia/reperfusion injury by decreasing oxyradical generation or by enhancing ATP levels. In separate laboratories, Kelner et al. (1988b) and Salaris et al. (1991) reported that MB suppressed the in vitro formation of cytotoxic oxygen free radical species by diverting electrons from xanthine oxidase. From the standpoint that the inhibition of free radical generation would eliminate major components of reperfusion-induced tissue damage, such a mechanism to preserve tissue viability and functional recovery was entirely plausible. In fact, this hypothetical mechanism was especially suitable for testing in our animal model in light of the confirmed presence of xanthine oxidase in the globally ischemic rat heart (Downey, 1988). Moreover, a xanthine oxidase inhibitor, allopurinol, has been reported to produce a beneficial effect in ischemic rat hearts, but whether this effect is actually due to the purported mechanism of allopurinol has not been unequivocally established in the literature. Our study, by determining the extent of membrane lipid peroxidation in tissue subjected to ischemia and reperfusion, provided no experimental evidence to support the contention that MB suppresses oxyradical formation. This finding correlated with the observed lack 
of significant functional cardioprotection, as assessed by the parameters of left ventricular pressure, heart rate, arrhythmia incidence, and cytosolic enzyme release.

Despite reports of its vasoconstrictive activity in select vascular beds, MB, even at high doses, did not decrease coronary flow. An observed decrease in flow would have more easily explained the poor recovery obtained in the treated heart preparations. But, in the absence of data to support coronary artery flow compromise, it is reasonable to conclude that $\mathrm{MB}$-induced vasoconstriction was not a major contributory factor for the results obtained in this study.

The lack of any detectable cardioprotection by methylene blue raises several questions, primarily focused on whether the current model is suitable and adequate to test the hypothesis. Prior to concluding that MB is not effective in attenuating ischemia and reperfusion damage, the author believes it would be prudent to repeat the experiments using the same biological system but with a modified protocol that shortens the duration of ischemia and lengthens the period of reperfusion. There is a distinct possibility, given the 35 minute period of global ischemia utilized in the present study, that there may be a critical timepoint after the onset of ischemia beyond which MB may be completely ineffective due to the irreversibility of cell death and the depletion or accumulation of metabolic byproducts. A repeat study using various durations of ischemia would confirm or rule out this possibility. In addition, to more thoroughly address the hypothesis that MB enhances ATP recovery, it is 
suggested that $\mathrm{MB}$ be tested in a protocol that includes a reperfusion period better defined to temporally allow for the synthesis and quantification of high energy phosphates.

It is equivocal as to why cardioprotection was not observed in the present EHNA study, as it has been in the past. However, previously unpublished data emanating from this laboratory, in studies of various chemical compounds, confirm that the present model allows the obervation of measurable and significant cardioprotection. Therefore, the presumed confidence in our model's ability to adequately test the hypothesis does allow for reasonable but prudent conclusions to be drawn about the lack of efficacy of MB in ischemia and reperfusion in our particular model.

In summary, the data do not support the hypothesis the MB attenuates damage caused by ischemia and reperfusion in our isolated rat heart model. However, future studies are necessary to evaluate the hypothesis under modified experimental conditions, as discussed above. 


\section{LIST OF REFERENCES}

Bolli, R. (1991). Oxygen-derived free radicals and myocardial reperfusion injury: an overview. Cardiovascular Drugs and Therapy, 5, 249-268.

Darley-Usmar, V., Stone, D., Smith, D., Martin, J. (1991). Mitochondria, oxygen and reperfusion damage. Annals of Medicine, 23, 583-588.

Downey, J., Hearse, D., Yellon, D. (1988). The role of xanthine oxidase during myocardial ischemia in several species including man. Journal of Molecular and Cellular Cardiology, 20(Suppl. II), 55-63.

Goldhaber, J. I., Weiss, J. N. (1992). Oxygen free radicals and cardiac reperfusion abnormalities. Hypertension, 20, 118-127.

Jennings, R. B., Reimer, K. A. (1991). The cell biology of acute myocardial ischemia. Annual Review of Medicine, 42, 225-246.

Karmazyn, M. (1991). Ischemic and reperfusion injury in the heart. Cellular mechanisms and pharmacological interventions. Canadian Journal of Physiological Pharmacology, 69, 719-730.

Katz, A. (1992). Physiology of the Heart (2nd ed.). New York: Raven Press.

Kelner, M., Bagnell, R., Hale, B., Alexander, N. (1988). Potential of methylene blue to block oxygen radical generation in reperfusion injury. Basic Life Sciences, 49, 895-898.

Kelner, M., Bagnell, R., Hale, B., Alexander, N. (1988). Methylene blue competes with paraquat for reduction by flavo-enzymes resulting in decreased superoxide production in the presence of heme proteins. Archives of Biochemistry and Biophysics, 262(2), 422-426.

Korthuis, R. J., Granger, D. N. (1993). Reactive oxygen metabolites, neutrophils, and the pathogenesis of ischemic tissue/reperfusion. Clinical Cardiology, 16, I19-I26.

Mahoney, J. R. (1990). Recovery of postischemic myocardial ATP levels and hexosemonophosphate shunt activity. Medical Hypotheses, 31, 21-23.

Salaris, S. C., Babbs, C. F., Voorhees, W. D. (1991). Methylene blue as an inhibitor of superoxide generation by xanthine oxidase. Biochemical Pharmacology, 42(3), 499-506. 
APPENDIX A. Introduction and Literature Review of the Problem 


\section{SPECIFIC OBJECTIVES}

The aim of this study was to determine the effects of methylene blue treatment on ischemia/reperfusion injury, as characterized by:

(1) Indices of cardiac electrical and mechanical performance

(2) Lactate dehydrogenase (LDH) activity in the coronary artery effluent as a marker of cellular membrane damage, cytosolic leakage, and myocardial cell necrosis

(3) Formation of thiobarbituric acid reactive substances (TBARS) in frozen cardiac tissue to estimate the extent of membrane lipid peroxidative injury 


\section{LITERATURE REVIEW}

Ischemia arises whenever coronary artery flow cannot provide oxygen and metabolic substrate in a quantity that is sufficient to meet the energy demands of myocardial tissue (Jennings \& Reimer, 1991; Downey, 1991). The consequences of ischemia entail a constellation of functional, structural, and metabolic derangements that are dependent on the duration and severity of coronary artery flow compromise (Downey, 1991).

Ischemia can result from a thrombotic or atherosclerotic occlusion of a coronary artery or may occur during surgical procedures, such as percutaneous transluminal coronary angioplasty (PTCA), cardiac transplantation, and coronary artery bypass grafting after cardioplegic arrest (Keith, 1993; Ferrari, 1992; Flitter, 1993). After an ischemic period longer than twenty minutes, some myocytes will sustain irreversible injury by the loss of plasma membrane integrity and leakage of cytosolic enzymes, such as LDH, culminating in necrosis and infarction (Jennings \& Reimer, 1991; Downey, 1990).

Manifestations of myocardial ischemia include 1) a sudden impairment in contractile function, 2) a decrease in intramyocardial pressure, 3) depletion of high energy phosphate stores (ATP) and accumulation of intracellular inorganic phosphate, 4) intracellular acidosis caused by proton and lactate accumulation, 5) hyperkalemia leading to arrhythmogenesis, and 6) a shift to anaerobic metabolism leading to the accumulation of glycolytic products (Jennings \& Reimer, 1991; Karmazyn, 1991; Katz, 1992). 
Timely reperfusion of the ischemic heart has been shown to reduce mortality and improve myocardial function in patients suffering from an infarction. However, under some circumstances, antiocclusive interventions such as pharmacological thrombolysis and coronary artery angioplasty (Goldhaber \& Weiss, 1992) may actually augment ischemic injury. Some clinical and experimental studies (Karmazyn, 1991; Downey, 1990) have revealed deleterious effects of reperfusion on myocardium, a paradoxical phenomenon marked by the occurrence of lethal arrhythmias such as ventricular fibrillation or ventricular tachycardia, massive cytosolic enzyme release, mechanical dysfunction leading to prolonged depression of contractile function, major ultrastructural damage, such as sarcolemmal disruption and mitochondrial swelling, cellular swelling, and cellular necrosis (Korthuis \& Granger, 1993; Hegstad et al., 1994; Goldhaber \& Weiss, 1992; Jeroudi et al., 1994). Since reperfusion must always be preceded by ischemia, and some of the adverse events may be related to the ischemic process and not exclusively to reperfusion itself, these events are collectively referred to as myocardial ischemia/reperfusion (I/R) injury (Karmazyn, 1991).

The ultimate mechanisms for the pathogenesis of damage to postischemic, reperfused hearts have not been fully elucidated. The etiology is multifactorial and involves a concerted series of events. Among the variety of proposed mechanisms, free radical-mediated oxidative damage and the derangement of cellular ion homeostasis have been implicated as the most 
significant contributors to the pathologic process.

The derangement of cellular ion homeostasis, especially intracellular calcium overload, has been reported to correlate with the adverse events that occur during reperfusion. On reflow, there is an extrusion of protons in exchange for $\mathrm{Na}^{+}$, via the $\mathrm{Na}^{+} / \mathrm{H}^{+}$exchanger, because of rapid washout of the acidic extracellular space. Intracellular $\mathrm{Na}^{+}$then accumulates and exchanges with calcium via the $3 \mathrm{Na}^{+} / \mathrm{Ca}^{+}$exchanger. Calcium accumulates excessively in the cytosol and mitochondria, resulting in depressed recovery of cellular functions due to impaired oxidative phosphorylation, impaired contractile function, arrhythmias, and phospholipid membrane breakdown (Tani, 1900; Tani \& Neely, 1989; Steenbergen et al., 1993; Pierce \& Meng, 1992). It has been reported that excessive mitochondrial calcium sequestration causes a decrease in electron transfer efficiency at $\mathrm{NADH} \mathrm{CoQ}$ reductase and complex I of the respiratory chain, resulting in a collapse of ionic homeostasis and diminished ATP synthesis on reoxygenation, culminating in cell death and lysis (DarleyUsmar et al., 1991). Studies using $\mathrm{Na}^{+} / \mathrm{H}^{+}$exchange inhibitors and calcium channel blockers have shown decreases in intracellular $\mathrm{Na}^{+}$and $\mathrm{Ca}^{++}$, paralleled by a reduction in arrhythmias and necrosis in ischemia and prevention of reperfusion-associated events (Ambrosio et al., 1992; Scholz \& Albus, 1993; Harper et al., 1993).

The occurrence of oxidative stress during reperfusion has been welldocumented. The formation of oxygen free radicals (OFR) (superoxide anion, 
hydrogen peroxide, nitric oxide radical, hydroxyl radical) during reperfusion has been directly identified by electron paramagnetic resonance spectroscopy and indirectly by the finding of malondialdehyde in tissue and coronary effluent (Maupoil et al., 1990; Darley-Usmar et al., 1991; Gauduel \& Duvelleroy, 1984). While endogenous antioxidant systems exist to neutralize OFR as a normal byproduct of aerobic metabolism, an imbalance between available protection and production of OFR leads to oxidative damage of organelles (Goldhaber \& Weiss, 1992).

Mitochondria are the predominant intracellular source of OFR (Flitter, 1993). During ischemia, the electron transport chain becomes fully reduced. On reoxygenation, mitochondria become reenergized. Electron egress through cytochrome $\mathrm{C}$ oxidase, which normally catalyzes the tetravalent reduction of oxygen, is inhibited, leading to augmented leakage of unpaired electrons which react with oxygen to form superoxide Piper et al., 1994; Ferrari et al., 1991).

Other sources of free radicals are polymorphonuclear leucocytes, or neutrophils, which contain a NADPH dependent oxidase system on the membrane surface that produces superoxide (Ferrari et al., 1991). This radical is stored in the cytoplasm and is released along with a latent chemoattractant that amplifies the inflammatory process during ischemia (Korthuis \& Granger, 1993; Kukreja \& Hess, 1992; Goldhaber \& Weiss, 1992). The contribution of this potential source of OFR is not relevant to the blood-free experimental system utilized in this project. 
The cytotoxicity of OFR is produced by an attack on polyunsaturated fatty acid chains complexed to phospholipid, resulting in the peroxidation of lipids and the consequential loss of cell integrity and function. By direct oxidation of amino acids and sulfhydryl groups, membrane proteins, subcellular functions, and critical enzymes in metabolic pathways may be irreversibly damaged (Flitter, 1993; Bolli, 1991; Romaschin et al., 1990). Arrhythmogenesis and precipitation of ventricular fibrillation appear due to an increase in membrane permeability, perturbations in calcium homeostasis, and modification of ionic translocating proteins in the sarcolemma and sarcoplasmic reticulum (Jeroudi et al., 1994; Bolli, 1991).

The potential for methylene blue (MB) to attenuate I/R injury has been proposed by several authors. Methylene blue, a commonly used redox dye, has been used in the treatment of methemoglobinemia, cyanide poisoning, nitrite poisoning, as a dye in abdominal surgery, and for detection of ischemic areas in the heart during surgery (Salaris et al., 1991; DiSanto \& Wagner, 1972a). The dye is partially lipid soluble, and in view of its routine use as a tissue stain, penetrates cell membranes readily (Kelner et al., 1988). It exhibits rapid cellular uptake in a dose-dependent fashion in several tissue and species types, including rat heart (DiSanto \& Wagner, 1972b). Once MB, in its original, colored form, is taken up by the cell, it is rapidly reduced to leukomethylene blue $(\mathrm{MB} 2 \mathrm{H})$, and it becomes colorless, less soluble, and accumulates in the intracellular compartment. This phenomenon, known as reductive trapping, 
accounts for the ability of cells to metabolize MB against its concentration gradient (Mahoney, 1990; DiSanto \& Wagner, 1972a). It is approved for human use and is easily available. Thus, its potential to attenuate the consequences of I/R injury should be explored.

Mahoney (1990) has postulated a mechanism of MB's potential to increase adenosine triphosphate (ATP) synthesis and improve recovery and function following ischemia and reperfusion. ATP recovery is dependent on either salvage of purine nucleotides for resynthesis or de novo biosynthesis. In ischemia, purine bases diffuse across the sarcolemmal membrane, making the salvage pathway ineffective, thereby forcing reliance on de novo biosynthesis. $\mathrm{MB}$, which oxidizes NADPH to $\mathrm{NADP}^{+}$, has been shown to increase hexosemonophosphate shunt (HMPS) activity more than twenty-fold in red blood cells. Therefore, an increase in flux through the HMPS should provide more phosphoribosylpyrophosphate (PRPP), an adenine nucleotide precursor, thereby enhancing functional recovery by more rapid ATP synthesis.

A hypothesis offered by Salaris et al. (1991) proposes that MB may exert an antioxidant effect in ischemia and reperfusion by competing with molecular oxygen for electrons in xanthine oxidase (XO). Xanthine dehydrogenase is converted by calcium-activated proteolysis to XO during ischemia, a time when hypoxanthine and xanthine are accumulating in cells as a consequence of ischemia-induced catabolism of adenine nucleotides. XO, a two subunit enzyme, contains three purine binding sites: flavin, molybdenum, and $\mathrm{Fe}-\mathrm{S}$ 
centers. In the normal sequence, electrons are routed to the flavin site, where molecular oxygen undergoes a single electron reduction to subsequently produce a burst of superoxide radicals (Hearse, 1991; Tavazzi et al., 1990), which can react with $\mathrm{H}_{2} \mathrm{O}_{2}$ and through the Fenton and Haber-Weiss reactions, generate the cytotoxic hydroxyl radical. Or, superoxide radical may react with nitric oxide radical to form the peroxynitrite anion, and subsequently undergo transformation to the hydroxyl radical (Kukreja \& Hess, 1992; Salaris et al., 1991; Downey et al., 1988).

MB, when administered prior to ischemia, may provide a substrate for further breakdown of adenine nucleotide metabolites and may short-circuit superoxide radical production by diverting electrons in xanthine oxidase (XO) from molecular oxygen at the flavin adenine dinucleotide (FAD) site (Salaris et al., 1991). MB, it is postulated, parasitically accepts electrons at the Fe-S center and becomes reduced to the leuko form (MB2H). In the presence of oxygen, MB2H autooxidizes back to MB with the concomitant formation of $\mathrm{H}_{2} \mathrm{O}_{2}$ rather than superoxide radical. There is insufficent $\mathrm{Fe}^{2+}$ to allow toxic amounts of hydroxyl radical formation from $\mathrm{H}_{2} \mathrm{O}_{2}$ by the Fenton reaction. Salaris et al. (1991) have showed significant MB concentration-related attenuation of membrane lipid peroxidation, as assessed by the thiobarbituric acid test, in liver and kidney tissue slices in an in vitro model of I/R injury.

While Salaris' hypothesis is attractive, its relevance in human myocardial I/R injury is uncertain, since evidence to support measurable XO activity in 
humans is inconsistent. While several studies have indicated no XO activity in human myocardium (Korthuis \& Granger, 1993; Kukreja\& Hess, 1992; Downey et al., 1988), others have suggested the possibility that the enzyme may not be in the oxidase form (Downey et al., 1988). However, the enzyme may be immunolocalized in capillary endothelial cells, which account for $1 \%$ of myocardial weight. Some studies have showed that XO inhibition, depletion, or immunoneutralization attenuates reperfusion injury in different models (Korthuis \& Grnager, 1993). However, in a rat model of myocardial I/R injury, XO activity never significantly increased during reperfusion (Coudray et al., 1992). This finding is inconsistent with the reported antiischemic effect of allopurinol, which purportedly acts by inhibiting XO (Korthuis \& Granger, 1993). Moreover, it has been reported that even with allopurinol treatment, which completely inhibited $\mathrm{XO}$, a massive release of $\mathrm{LDH}$ was still seen during reperfusion (Kehrer et al., 1987).

Hrushesky (1985) showed that levels of reduced glutathione (GSH) in cardiac and hepatic tissue were lower in animals treated with MB than in salinetreated animals. The decrease in GSH has been attributed to competition with GSSG for NADPH, thereby inhibiting the reduction of GSSG to GSH, and lowering the overall cellular reducing capacity. Kelner and Alexander (1985) have reported, however, that $\mathrm{MB}$ directly oxidizes glutathione without the intermediate formation of hydrogen peroxide that occurs with MB reduction. Since GSH plays an essential protective role against OFR and prevents 
membrane lipid peroxidation (Ferrari et al., 1991), the implications of Kelner's and Alexander's data are ambiguous concerning the potential protective role of $M B$ in $\mathrm{I} / \mathrm{R}$ injury.

Kelner et al. (1988) have also reported that methylene blue competed effectively with paraquat, a free radical-producing herbicide, for reduction with the flavin-containing enzymes, xanthine oxidase, NADH cytochrome C reductase, and $\mathrm{NADPH}$-dependent $\mathrm{p} 450$ reductase. Methylene blue was shown to react with heme proteins rather than with molecular oxygen, thereby decreasing the formation of superoxide and hydoxyl radical.

In summary, a search of the literature has revealed no previous research on the effects of methylene blue treatment in global myocardial ischemia and reperfusion in an animal model. Therefore, this study was undertaken to investigate the potential attenuation of damage associated with ischemia and reperfusion in the isolated rat heart. 
APPENDIX B. SUMMARY OF RAW DATA AND STATISTICAL ANALYSES 
Table 2. A Summary of Raw Data for the Duration (in minutes) of Ventricular Fibrillation during Reperfusion.

\begin{tabular}{|c|c|c|c|c|}
\hline Heart & Untreated & MB $0.1 \mu \mathrm{M}$ & MB $1.0 \mu \mathrm{M}$ & MB $10.0 \mu \mathrm{M}$ \\
\hline 1 & 10 & 10 & 4 & 9 \\
\hline 2 & 0 & 8 & 0 & 0 \\
\hline 3 & 1 & 10 & 0 & 9 \\
\hline 4 & 0 & 10 & 10 & 0 \\
\hline 5 & 10 & 10 & 4.5 & 0 \\
\hline 6 & 0 & 10 & 10 & 10 \\
\hline 7 & 8.5 & 10 & 0 & 10 \\
\hline 8 & 10 & 10 & 0 & 10 \\
\hline 9 & 0 & 10 & 10 & 10 \\
\hline 10 & 0 & & & \\
\hline 11 & 10 & & & \\
\hline 12 & 10 & & & \\
\hline 13 & 10 & & & \\
\hline 14 & 10 & & & \\
\hline 15 & 10 & & & \\
\hline 16 & 10 & & & \\
\hline 17 & 0 & & & \\
\hline 18 & 10 & & & \\
\hline 19 & 10 & & & \\
\hline 20 & 0 & & & \\
\hline 21 & 10 & & & \\
\hline 22 & 0 & & & \\
\hline 23 & 10 & & & \\
\hline 24 & 10 & & & \\
\hline 25 & 10 & & & \\
\hline 26 & 10 & & & \\
\hline 27 & 10 & & & \\
\hline 28 & 10 & & & \\
\hline 29 & 0 & & & \\
\hline 30 & 0 & & & \\
\hline 31 & 10 & & & \\
\hline 32 & 1.87 & & & \\
\hline Mean & 6.29 & 9.78 & 4.28 & 6.44 \\
\hline SD & 4.78 & 0.67 & 4.63 & 4.85 \\
\hline Incidence & $68.8 \%$ & $100 \%$ & $55.5 \%$ & $66.6 \%$ \\
\hline
\end{tabular}




\section{Statistical Analysis of Ventricular Fibrillation Duration during Reperfusion}

LEVELS ENCOUNTERED DURING PROCESSING ARE:

$$
\begin{array}{ll}
\frac{\text { HEART }}{1.000} & \text { Untreated } \\
2.000 & 0.1 \mathrm{uM} \mathrm{MB} \\
3.000 & 1.0 \mathrm{MM} \mathrm{MB} \\
4.000 & 10.0 \mathrm{uM} \mathrm{MB}
\end{array}
$$

DEP VAR: DURATION N: 59 MULTIPLE R: 0.342

SQUARED MULTIPLE R: 0.117

ANALYSIS OF VARIANCE

SOURCE SUM-OF-SQUARES DF MEAN-SQUARE F-RATIO

$\begin{array}{llcccc}\text { HEART } & 142.445 & 3 & 47.482 & 2.434 & 0.075 \\ \text { ERROR } & 1072.897 & 55 & 19.507 & & \end{array}$

LEAST SQUARES MEANS.

$\begin{array}{rlccr} & & \text { LS MEAN } & \text { SE } & \text { N } \\ \text { HEART } & =1.000 & 6.293 & 0.781 & 32 \\ \text { HEART }= & 2.000 & 9.778 & 1.472 & 9 \\ \text { HEART }= & 3.000 & 4.278 & 1.472 & 9 \\ \text { HEART }= & 4.000 & 6.444 & 1.472 & 9\end{array}$

POST HOC TEST OF DURATION

DUNNETT TEST WITH CONTROL $=1.000$

USING MODEL MSE OF 19.507 WITH 55. DF.

MATRIX OF MEAN DIFFERENCES FROM CONTROL:

$$
\begin{array}{rr}
1 & 0.000 \\
2 & 3.485 \\
3 & -2.015 \\
4 & 0.152
\end{array}
$$

DUNNETT TWO SIDED TEST

MATRIX OF PAIRWISE COMPARISON PROBABILITIES:

$\begin{array}{ll}1 & 1.000 \\ 2 & 0.115 \\ 3 & 0.531 \\ 4 & 1.000\end{array}$


Statistical Analysis of Ventricular Fibrillation Incidence during Reperfusion

LEVELS ENCOUNTERED DURING PROCESSING ARE:

$\begin{array}{ll}\frac{\text { HEART }}{1.000} & \text { Untreated } \\ 2.000 & 0.1 \mathrm{UM} \mathrm{MB} \\ 3.000 & 1.0 \mathrm{MM} \mathrm{MB} \\ 4.000 & 10.0 \mathrm{MM} \mathrm{MB}\end{array}$

DEP VAR: INCIDENCE N: 59 MULTIPLE R: 0.288

SQUARED MULTIPLE R: 0.083

ANALYSIS OF VARIANCE

SOURCE SUM-OF-SQUARES DF MEAN-SQUARE F-RATIO $\underline{P}$

$\begin{array}{llllll}\text { HEART } & 1.004 & 3 & 0.335 & 1.659 & 0.186 \\ \text { ERROR } & 11.097 & 55 & 0.202 & & \end{array}$

LEAST SQUARES MEANS.

$\begin{array}{lllll} & & \text { LS MEAN } & \text { SE } & \text { N } \\ \text { HEART } & =1.000 & 0.688 & 0.079 & 32 \\ \text { HEART } & =2.000 & 1.000 & 0.150 & 9 \\ \text { HEART } & =3.000 & 0.556 & 0.150 & 9 \\ \text { HEART } & =4.000 & 0.667 & 0.150 & 9\end{array}$

POST HOC TEST OF INCIDENCE

DUNNETT TEST WITH CONTROL $=1.000$

USING MODEL MSE OF .202 WITH 55 DF.

MATRIX OF MEAN DIFFERENCES FROM CONTROL:

$\begin{array}{rr}1 & 0.000 \\ 2 & 0.313 \\ 3 & -0.132 \\ 4 & -0.021\end{array}$

DUNNETT TWO SIDED TEST.

MATRIX OF PAIRWISE COMPARISON PROBABILITIES:

$\begin{array}{ll}1 & 1.000 \\ 2 & 0.190 \\ 3 & 0.813 \\ 4 & 0.999\end{array}$


Table 3. A Summary of Calculated Indices of Electromechanical Recovery

\begin{tabular}{|c|c|c|c|c|}
\hline Heart & Untreated & MB $0.1 \mu \mathrm{M}$ & MB 1.0 $\mu \mathrm{M}$ & MB $10.0 \mu M$ \\
\hline 1 & 0.0000 & 0.0000 & 0.0000 & 0.0330 \\
\hline 2 & 0.7674 & 0.0670 & 0.7800 & 0.4960 \\
\hline 3 & 0.7995 & 0.0000 & 0.8191 & 0.0330 \\
\hline 4 & 0.6007 & 0.0000 & 0.6896 & 0.6390 \\
\hline 5 & 0.0000 & 0.0310 & 0.0000 & 0.6220 \\
\hline 6 & 0.7235 & 0.0180 & 0.1833 & 0.0000 \\
\hline 7 & 0.0500 & 0.0260 & 0.0000 & 0.0000 \\
\hline 8 & 0.0000 & 0.0350 & 0.8224 & 0.0000 \\
\hline 9 & 0.7463 & 0.0310 & 0.4505 & 0.0000 \\
\hline 10 & 0.5907 & & & \\
\hline 11 & 0.0000 & & & \\
\hline 12 & 0.0000 & & & \\
\hline 13 & 0.0000 & & & \\
\hline 14 & 0.0000 & & & \\
\hline 15 & 0.0000 & & & \\
\hline 17 & 0.8564 & & & \\
\hline 18 & 0.6762 & & & \\
\hline 19 & 0.0000 & & & \\
\hline 20 & 0.7220 & & & \\
\hline 21 & 0.0000 & & & \\
\hline 22 & 0.9360 & & & \\
\hline 23 & 0.0000 & & . & \\
\hline 24 & 0.0000 & & & \\
\hline 25 & 0.0000 & & & \\
\hline 26 & 0.0000 & & & \\
\hline 27 & 0.0330 & & & \\
\hline 28 & 0.0230 & & & \\
\hline 29 & 0.7519 & & & \\
\hline 30 & 0.7315 & & & \\
\hline 31 & 0.0000 & & & \\
\hline 32 & 0.2870 & & & \\
\hline Mean & .0 .29047 & .02311 & .41610 & .20256 \\
\hline SD & 0.36338 & .02188 & .37241 & .29029 \\
\hline
\end{tabular}




\section{Statistical Analysis of Indices of Electromechanical Recovery}

LEVELS ENCOUNTERED DURING PROCESSING ARE:

$\begin{array}{ll}\frac{\text { HEART }}{1.000} & \text { Untreated } \\ 2.000 & 0.1 \mathrm{uM} \mathrm{MB} \\ 3.000 & 1.0 \mathrm{uM} \mathrm{MB} \\ 4.000 & 10.0 \mathrm{MM} \mathrm{MB}\end{array}$

DEP VAR: INDEX OF ELECTROMECHANICAL RECOVERY N: 59

MULTIPLE R: 0.343 SQUARED MULTIPLE R: 0.117

\section{ANALYSIS OF VARIANCE}

$\underline{\text { SOURCE SUM-OF-SQUARES }}$ DF MEAN-SQUARE F-RATIO $\underline{P}$

$\begin{array}{llllll}\text { HEART } & 0.783 & 3 & 0.261 & 2.440 & 0.074 \\ \text { ERROR } & 5.881 & 55 & 0.107 & & \end{array}$

LEAST SQUARES MEANS

$\begin{array}{lllll} & & \text { LS MEAN } & \text { SE } & \mathrm{N} \\ \text { HEART } & =1.000 & 0.290 & 0.058 & 32 \\ \text { HEART } & =2.000 & 0.023 & 0.109 & 9 \\ \text { HEART } & =3.000 & 0.416 & 0.109 & 9 \\ \text { HEART } & =4.000 & 0.203 & 0.109 & 9\end{array}$

POST HOC TEST OF INDEX OF ELECTROMECHANICAL RECOVERY DUNNETT TEST WITH CONTROL $=\quad 1.000$

USING MODEL MSE OF .107 WITH 55 DF.

MATRIX OF MEAN DIFFERENCES FROM CONTROL:

$\begin{array}{lr}1 & 0.000 \\ 2 & -0.267 \\ 3 & 0.126 \\ 4 & -0.088\end{array}$

DUNNETT TWO SIDED TEST.

MATRIX OF PAIRWISE COMPARISON PROBABILITIES:

$\begin{array}{ll}1 & 1.000 \\ 2 & 0.097 \\ 3 & 0.661 \\ 4 & 0.849\end{array}$




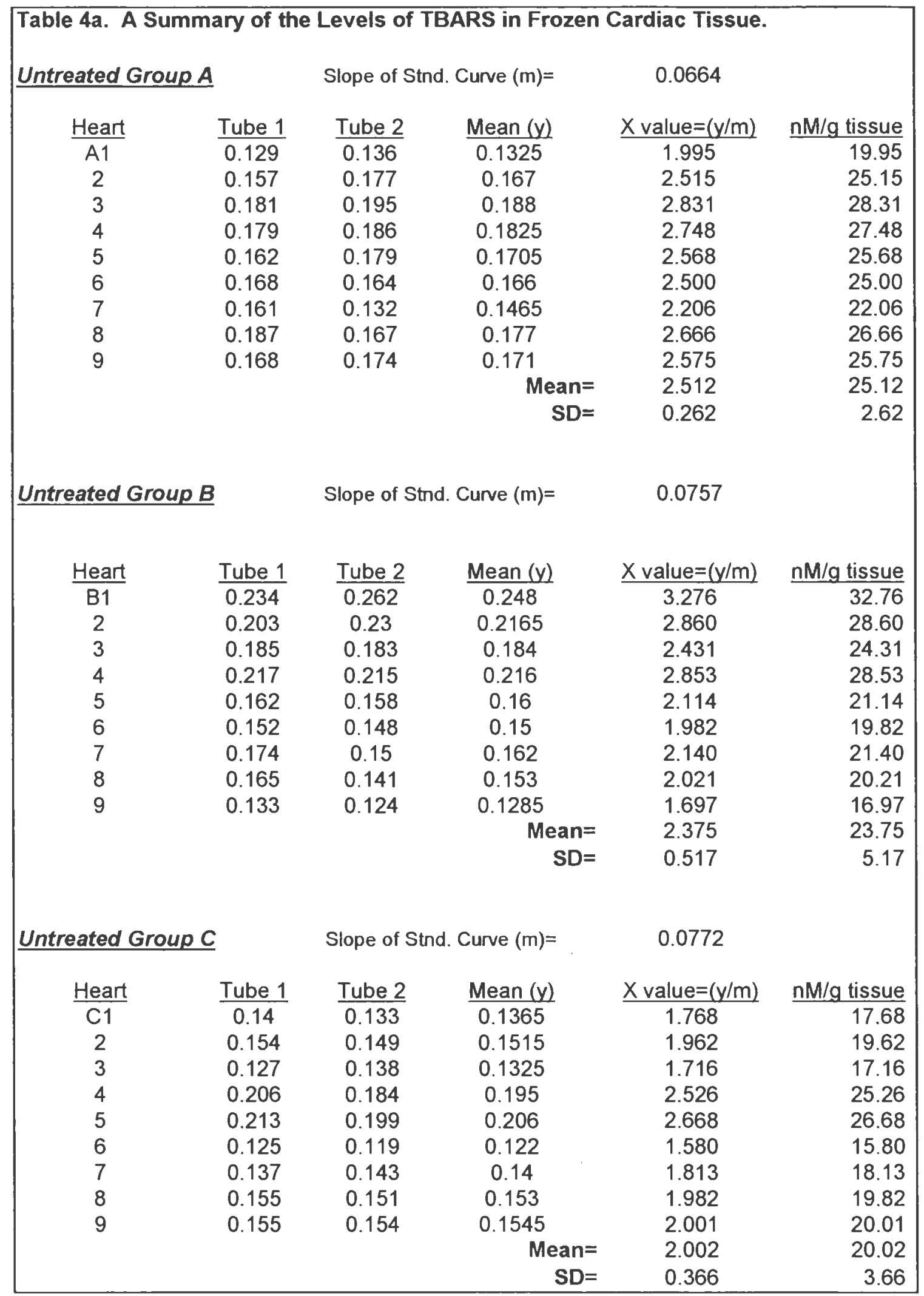




\begin{tabular}{|c|c|c|c|c|c|}
\hline Untreated Grol & & Slope of & Curve $(m)=$ & 0.0768 & \\
\hline Heart & Tube 1 & Tube 2 & $\operatorname{Mean}(\mathrm{v})$ & $X$ value $=(y / m)$ & $\mathrm{nM} / \mathrm{g}$ tissue \\
\hline 1 & 0.167 & $\overline{0.173}$ & 0.17 & 2.214 & 22.14 \\
\hline 2 & 0.154 & 0.147 & 0.1505 & 1.960 & 19.60 \\
\hline 3 & 0.178 & 0.181 & 0.1795 & 2.337 & 23.37 \\
\hline 4 & 0.169 & 0.163 & 0.166 & 2.161 & 21.61 \\
\hline 5 & 0.146 & 0.152 & 0.149 & 1.940 & 19.40 \\
\hline & & & Mean= & 2.122 & 21.224 \\
\hline & & & $\mathrm{SD}=$ & 0.170 & 1.701 \\
\hline Pooled Mean= & $22.69 n n$ & tissue & & & \\
\hline Pooled SD = & 4.120 & & & & \\
\hline
\end{tabular}




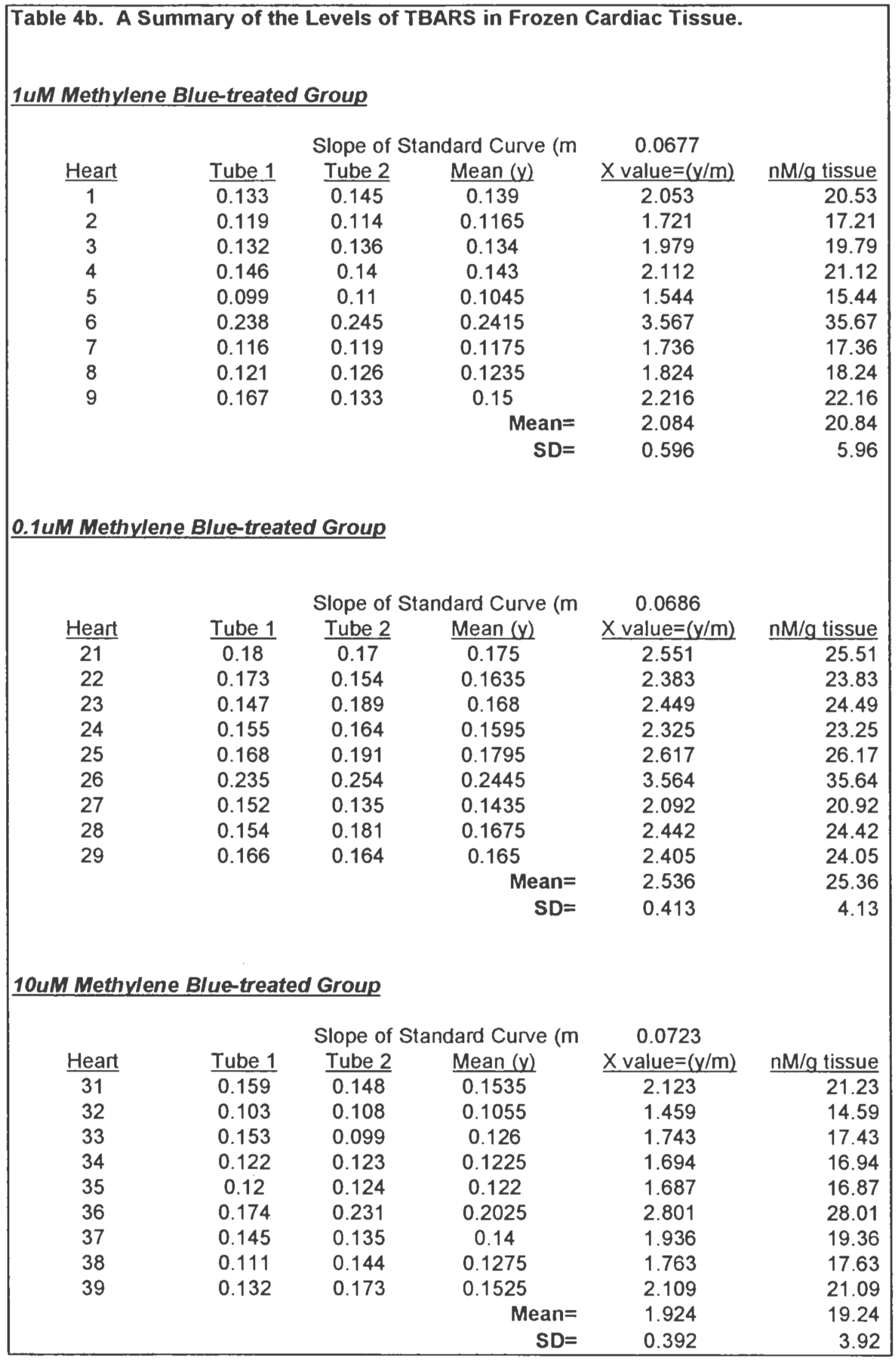


Statistical Analysis of the Levels of TBARS in Frozen Cardiac Tissue at the End of Reperfusion

LEVELS ENCOUNTERED DURING PROCESSING ARE:

HEART

1.000 Untreated

$2.000 \quad 0.1 \mathrm{uM} \mathrm{MB}$

$3.000 \quad 1.0 u M M B$

4.000 10.0uM MB

DEP VAR: TBARS N: 59 MULTIPLE R: 0.391 SQUARED MULTIPLE R: 0.153

ANALYSIS OF VARIANCE

SOURCE SUM-OF-SQUARES DF MEAN-SQUARE F-RATIO P

$\begin{array}{llllll}\text { HEART } & 192.996 & 3 & 64.332 & 3.310 & 0.027\end{array}$

ERROR

$\begin{array}{lll}1068.823 & 55 & 19.433\end{array}$

LEAST SQUARES MEANS

$\begin{array}{lllll} & & \text { LS MEAN } & \text { SE } & \mathrm{N} \\ \text { HEART } & =1.000 & 22.689 & 0.779 & 32 \\ \text { HEART } & =2.000 & 25.364 & 1.469 & 9 \\ \text { HEART } & =3.000 & 20.836 & 1.469 & 9 \\ \text { HEART } & =4.000 & 19.239 & 1.469 & 9\end{array}$

POST HOC TEST OF TBARS

DUNNETT TEST WITH CONTROL $=\quad 1.000$

USING MODEL MSE OF 19.433 WITH 55 DF

MATRIX OF MEAN DIFFERENCES FROM CONTROL:

$\begin{array}{ll}1 & 0.000 \\ 2 & 2.675 \\ 3 & -1.854 \\ 4 & -3.450\end{array}$

DUNNETT TWO SIDED TEST.

MATRIX OF PAIRWISE COMPARISON PROBABILITIES:

$\begin{array}{ll}1 & 1.000 \\ 2 & 0.293 \\ 3 & 0.595 \\ 4 & 0.119\end{array}$


Table 5a. Coronary Artery Flow Rates (ml/minute $\times \mathrm{g}$ wet heart weight)

Untreated Group

\begin{tabular}{|c|c|c|c|c|c|c|c|c|c|c|}
\hline \multirow[b]{2}{*}{ Heart } & \multicolumn{3}{|c|}{ Pre-ischemia } & \multicolumn{7}{|c|}{ Time Point during Reperfusion } \\
\hline & $\underline{\mathbf{0}}$ & $\underline{5}$ & $q$ & 46 & $\underline{47}$ & $\underline{48}$ & 49 & $\underline{50}$ & $\underline{52}$ & $\underline{55}$ \\
\hline 1 & 6.26 & 4.56 & 3.27 & 0.74 & 0.69 & 0.77 & 0.79 & 0.80 & 0.75 & 0.73 \\
\hline 2 & 5.85 & 4.84 & 3.92 & 0.78 & 0.93 & 0.95 & 0.86 & 0.66 & 0.48 & 0.47 \\
\hline 3 & 4.17 & 3.21 & 2.48 & 0.55 & 0.78 & 0.93 & 1.17 & 1.16 & 1.24 & 1.32 \\
\hline 4 & 4.59 & 5.13 & 3.98 & 0.91 & 1.45 & 1.40 & 1.33 & 1.25 & 1.37 & 1.39 \\
\hline 5 & 4.89 & 4.30 & 4.30 & 1.85 & 1.33 & 1.75 & 2.14 & 2.36 & 2.23 & 2.37 \\
\hline 6 & 6.12 & 3.87 & 3.54 & 1.19 & 1.31 & 1.22 & 1.20 & 1.18 & 1.20 & 1.30 \\
\hline 7 & 4.32 & 3.82 & 3.32 & 0.67 & 0.58 & 0.58 & 0.68 & 0.75 & 1.14 & 1.07 \\
\hline 8 & 5.34 & 4.31 & 3.53 & 0.76 & 0.99 & 0.91 & 0.81 & 0.68 & 0.63 & 0.50 \\
\hline 9 & 3.74 & 3.61 & 3.83 & 1.74 & 1.71 & 1.58 & 1.80 & 1.95 & 2.05 & 1.78 \\
\hline 10 & 6.51 & 5.66 & 4.22 & 1.15 & 1.13 & 0.85 & 0.85 & 0.95 & 0.95 & 0.96 \\
\hline 11 & 3.43 & 3.35 & 3.02 & 0.54 & 0.73 & 0.71 & 0.67 & 0.74 & 0.93 & 1.24 \\
\hline 12 & 6.75 & 6.88 & 6.16 & 1.19 & 1.17 & 0.99 & 0.75 & 0.65 & 0.61 & 0.63 \\
\hline 13 & 6.31 & 4.51 & 3.78 & 1.13 & 1.20 & 1.24 & 1.10 & 1.00 & 1.09 & 1.35 \\
\hline 14 & 8.31 & 7.72 & 5.20 & 1.09 & 0.62 & 0.52 & 0.49 & 0.49 & 0.59 & 0.64 \\
\hline 15 & 8.35 & 7.95 & 7.12 & 1.12 & 1.66 & 1.45 & 1.25 & 1.18 & 1.23 & 1.39 \\
\hline 16 & 6.57 & 6.24 & 5.78 & 1.43 & 0.71 & 0.72 & 0.87 & 1.54 & 1.22 & 1.17 \\
\hline 17 & 2.57 & 3.92 & 2.62 & 1.06 & 1.42 & 1.87 & 1.90 & 2.26 & 2.28 & 2.65 \\
\hline 18 & 3.48 & 2.41 & 2.10 & 0.83 & 1.10 & 1.02 & 0.98 & 1.12 & 1.12 & 0.91 \\
\hline 19 & 5.82 & 5.36 & 4.32 & 0.90 & 1.00 & 0.98 & 0.87 & 0.86 & 0.62 & 1.13 \\
\hline 20 & 2.31 & 1.73 & 1.28 & 1.33 & 1.29 & 1.24 & 1.03 & 0.98 & 0.97 & 0.89 \\
\hline 21 & 4.62 & 3.67 & 3.03 & 0.70 & 0.78 & 0.60 & 0.50 & 0.46 & 0.51 & 0.57 \\
\hline 22 & 7.24 & 7.35 & 6.90 & 9.39 & 8.39 & 8.28 & 7.85 & 8.18 & 8.40 & 8.62 \\
\hline 23 & 6.47 & 8.15 & 8.99 & 1.33 & 1.28 & 1.04 & 1.46 & 1.43 & 2.07 & 1.82 \\
\hline 24 & 5.75 & 5.24 & 5.12 & 1.06 & 0.75 & 0.57 & 0.48 & 0.48 & 0.54 & 0.66 \\
\hline 25 & 7.06 & 6.96 & 6.61 & 1.62 & 1.09 & 0.84 & 0.77 & 0.84 & 1.16 & 1.26 \\
\hline 26 & 8.65 & 9.88 & 9.52 & 3.07 & 2.79 & 3.03 & 3.06 & 3.19 & 3.44 & 3.35 \\
\hline 27 & 7.29 & 6.53 & 5.84 & 1.15 & 1.14 & 0.91 & 0.77 & 0.63 & 0.41 & 0.47 \\
\hline 28 & 7.91 & 7.73 & 5.96 & 1.36 & 1.27 & 1.42 & 1.67 & 1.79 & 2.00 & 2.01 \\
\hline 29 & 4.21 & 3.82 & 3.33 & 0.95 & 1.31 & 1.28 & 1.22 & 1.27 & 1.31 & 1.40 \\
\hline 30 & 7.24 & 6.89 & 6.66 & 4.11 & 3.95 & 3.96 & 3.94 & 3.70 & 3.82 & 3.75 \\
\hline 31 & 6.80 & 5.27 & 4.01 & 0.84 & 1.09 & 1.09 & 1.03 & 0.96 & 0.95 & 1.07 \\
\hline 32 & 4.47 & 4.65 & 4.31 & 1.09 & 1.14 & 0.99 & 1.03 & 1.07 & 1.14 & 1.03 \\
\hline Mean & 5.73 & 5.30 & 4.63 & 1.49 & 1.46 & 1.43 & 1.42 & 1.45 & 1.51 & 1.56 \\
\hline SD & 1.69 & 1.88 & 1.90 & 1.61 & 1.42 & 1.43 & 1.38 & 1.44 & 1.49 & 1.51 \\
\hline
\end{tabular}




\begin{tabular}{|c|c|c|c|c|c|c|c|c|c|c|}
\hline \multirow[b]{4}{*}{ Heart } & \multicolumn{10}{|c|}{ Table 5b. Coronary Artery Flow Rates (mL/minute $\times \mathrm{g}$ wet heart weight) } \\
\hline & \multicolumn{10}{|c|}{ Methylene Blue [1.0uM]-treated Hearts } \\
\hline & \multicolumn{3}{|c|}{ Pre-ischemia } & \multicolumn{7}{|c|}{ Time Point during Reperfusion } \\
\hline & $\underline{\mathbf{0}}$ & $\underline{\mathbf{5}}$ & $\underline{9}$ & $\underline{46}$ & $\underline{47}$ & $\underline{48}$ & 49 & $\underline{50}$ & $\underline{52}$ & $\underline{55}$ \\
\hline MB1 & 4.96 & $4 . \overline{1}$ & $4.3 \overline{8}$ & $1 . \overline{32}$ & $1 . \overline{28}$ & $1 . \overline{57}$ & $1 . \overline{47}$ & $1 . \overline{92}$ & 2.06 & $2 . \overrightarrow{19}$ \\
\hline 2 & 6.53 & 6.29 & 6.09 & 0.47 & 0.41 & 0.53 & 0.87 & 4.63 & 4.46 & 4.54 \\
\hline 3 & 5.34 & 4.63 & 4.62 & 0.85 & 1.36 & 1.52 & 1.52 & 1.56 & 1.14 & 0.84 \\
\hline 4 & 4.52 & 4.50 & 4.63 & 1.35 & 1.16 & 0.67 & 0.51 & 0.63 & 0.64 & 0.63 \\
\hline 5 & 3.27 & 3.49 & 2.98 & 0.46 & 0.72 & 0.47 & 0.36 & 0.39 & 0.46 & 0.60 \\
\hline 6 & 3.72 & 2.61 & 2.86 & 0.72 & 1.62 & 1.70 & 1.71 & 1.71 & 1.91 & 1.78 \\
\hline 7 & 5.46 & 5.21 & 4.22 & 1.77 & 2.14 & 1.97 & 1.92 & 1.93 & 1.97 & 2.27 \\
\hline 8 & 2.17 & 2.41 & 2.03 & 1.00 & 0.65 & 0.49 & 0.43 & 0.38 & 0.71 & 0.29 \\
\hline 9 & 7.41 & 6.76 & 5.50 & 1.37 & 1.76 & 1.67 & 1.69 & 1.46 & 1.58 & 1.71 \\
\hline Mean & 4.82 & 4.50 & 4.15 & 1.03 & 1.23 & 1.18 & 1.16 & 1.62 & 1.66 & 1.65 \\
\hline \multirow[t]{4}{*}{ SD } & 1.62 & 1.49 & 1.31 & 0.45 & 0.56 & 0.62 & 0.62 & 1.29 & 1.22 & 1.31 \\
\hline & \multicolumn{10}{|c|}{ Methylene Blue [0.1uM]-treated Hearts } \\
\hline & \multicolumn{3}{|c|}{ Pre-ischemia } & \multicolumn{7}{|c|}{ Time Point during Reperfusion } \\
\hline & $\underline{\mathbf{0}}$ & $\underline{\mathbf{5}}$ & $\underline{9}$ & $\underline{46}$ & $\underline{47}$ & $\underline{48}$ & 49 & $\underline{50}$ & $\underline{52}$ & $\underline{\mathbf{5 5}}$ \\
\hline MB21 & 2.47 & 2.40 & 1.97 & $0 . \overline{91}$ & $0 . \overline{65}$ & $0 . \overline{41}$ & 0.37 & $0 . \overline{37}$ & $0 . \overline{43}$ & $0 . \overline{47}$ \\
\hline 22 & 5.38 & 4.48 & 3.75 & 1.50 & 1.05 & 0.69 & 0.68 & 0.45 & 0.36 & 0.34 \\
\hline 23 & 7.66 & 6.12 & 5.55 & 2.76 & 2.67 & 2.75 & 2.93 & 2.92 & 3.18 & 2.91 \\
\hline 24 & 6.11 & 5.30 & 3.93 & 0.33 & 0.45 & 0.42 & 0.36 & 0.40 & 0.36 & 0.39 \\
\hline 25 & 9.87 & 9.66 & 9.00 & 1.48 & 1.64 & 0.75 & 0.62 & 0.60 & 1.02 & 1.84 \\
\hline 26 & 8.01 & 8.42 & 4.60 & 0.97 & 1.06 & 0.97 & 0.84 & 1.23 & 2.25 & 1.33 \\
\hline 27 & 8.52 & 7.16 & 5.79 & 0.77 & 0.65 & 1.19 & 1.21 & 1.13 & 1.04 & 1.15 \\
\hline 28 & 6.19 & 4.52 & 3.86 & 0.87 & 1.04 & 0.94 & 0.80 & 0.65 & 0.67 & 0.80 \\
\hline 29 & 7.42 & 7.47 & 6.63 & 0.97 & 0.78 & 0.55 & 0.73 & 0.83 & 0.73 & 1.41 \\
\hline Mean & 6.85 & 6.17 & 5.01 & 1.17 & 1.11 & 0.96 & 0.95 & 0.95 & 1.12 & 1.18 \\
\hline SD & 2.14 & 2.25 & 2.03 & 0.69 & 0.68 & 0.72 & 0.79 & 0.80 & 0.97 & 0.83 \\
\hline \multicolumn{11}{|c|}{ Methylene Blue [10.0uM]-treated Hearts } \\
\hline & \multicolumn{3}{|c|}{ Prefischemia } & \multicolumn{7}{|c|}{ Time Point during Reperfusion } \\
\hline & $\underline{\mathbf{0}}$ & $\underline{5}$ & $\underline{9}$ & $\underline{46}$ & 47 & 48 & 49 & $\underline{50}$ & $\underline{52}$ & $\underline{55}$ \\
\hline MB31 & $9.9 \overline{3}$ & $8.3 \overline{7}$ & 7.25 & $1 . \overline{53}$ & $1 . \overline{87}$ & $0 . \overline{84}$ & $0 . \overline{67}$ & $0 . \overline{67}$ & $0 . \overline{84}$ & $0 . \overline{86}$ \\
\hline 32 & 9.60 & 8.70 & 7.10 & 0.66 & 1.39 & 1.72 & 1.65 & 1.64 & 1.56 & 1.64 \\
\hline 33 & 6.02 & 6.32 & 5.83 & 1.12 & 0.83 & 0.50 & 0.67 & 0.64 & 0.55 & 0.59 \\
\hline 34 & 5.98 & 5.68 & 6.01 & 1.02 & 0.72 & 0.41 & 0.29 & 0.30 & 0.56 & 0.60 \\
\hline 35 & 6.25 & 7.23 & 7.78 & 3.22 & 3.06 & 2.99 & 2.78 & 2.89 & 3.15 & 3.16 \\
\hline 36 & 6.90 & 5.67 & 5.24 & 1.19 & 1.85 & 1.60 & 1.54 & 1.59 & 1.58 & 1.53 \\
\hline 37 & 8.38 & 7.56 & 5.98 & 0.95 & 0.82 & 0.79 & 0.88 & 1.08 & 1.03 & 1.30 \\
\hline 38 & 9.54 & 7.88 & 9.91 & 0.76 & 1.15 & 0.83 & 0.66 & 0.67 & 0.61 & 0.74 \\
\hline 39 & 8.33 & 8.06 & 7.47 & 0.70 & 0.96 & 0.85 & 0.92 & 0.79 & 0.85 & 1.36 \\
\hline Mean & 7.88 & 7.27 & 6.95 & 1.24 & 1.41 & 1.17 & 1.12 & 1.14 & 1.19 & 1.31 \\
\hline SD & 1.62 & 1.14 & 1.41 & 0.79 & 0.76 & 0.81 & 0.76 & 0.79 & 0.83 & 0.80 \\
\hline
\end{tabular}


NUMBER OF CASES PROCESSED: $\quad 59$

DEPENDENT VARIABLE MEANS

$\begin{array}{ccccccc}\text { T46 } & \text { T47 } & \text { T48 } & \text { T49 } & \text { T50 } & \text { T52 } & \text { T55 } \\ 1.323 & 1.320 & 1.248 & 1.235 & 1.328 & 1.415 & 1.458\end{array}$

LEAST SQUARES MEANS.

\begin{tabular}{lccccc} 
HEART $=1.000$ & \multicolumn{5}{c}{ N OF CASES $=32.000$} \\
& T46 & T47 & T48 & T49 & T50 \\
LS. MEAN & 1.488 & 1.462 & 1.428 & 1.416 & 1.455 \\
SE & 0.225 & 0.203 & 0.206 & 0.203 & 0.223 \\
& & & & & \\
LS. MEAN & T52 & T55 & & & \\
SE & 1.514 & 1.559 & & &
\end{tabular}

HEART $=2.000 \quad$ N OF CASES $=9.000$

$\begin{array}{lccccc} & \text { T46 } & \text { T47 } & \text { T48 } & \text { T49 } & \text { T50 } \\ \text { LS. MEAN } & 1.173 & 1.110 & 0.963 & 0.949 & 0.953 \\ \text { SE } & 0.425 & 0.382 & 0.389 & 0.382 & 0.421\end{array}$

$\begin{array}{lcc} & \text { T52 } & \text { T55 } \\ \text { LS. MEAN } & 1.116 & 1.182 \\ \text { SE } & 0.440 & 0.438\end{array}$

HEART $=3.000 \quad$ N OF CASES $=9.000$

$\begin{array}{lccccc} & \text { T46 } & \text { T47 } & \text { T48 } & \text { T49 } & \text { T50 } \\ \text { LS. MEAN } & 1.034 & 1.233 & 1.177 & 1.164 & 1.623 \\ \text { SE } & 0.425 & 0.382 & 0.389 & 0.382 & 0.421\end{array}$

LS. MEAN $1.659 \quad 1.650$

$\begin{array}{lll}\text { SE } & 0.440 \quad 0.438\end{array}$




\begin{tabular}{lccccc} 
HEART $=4.000$ & \multicolumn{5}{c}{ N OF CASES $=$} \\
& T46 & T47 & T48 & T49 & T50 \\
LS. MEAN & 1.173 & 1.110 & 0.963 & 0.949 & 0.953 \\
SE & 0.425 & 0.382 & 0.389 & 0.382 & 0.421 \\
& & & & & \\
LS. MEAN & 1.116 & 1.182 & & & \\
SE & 0.440 & 0.438 & & &
\end{tabular}

UNIVARIATE AND MULTIVARIATE REPEATED MEASURES ANALYSIS

BETWEEN SUBJECTS

$\begin{array}{llllll}\text { SOURCE } & \text { SS } & \text { DF } & \text { MS } & F & P\end{array}$

$\begin{array}{llcccc}\text { HEART } & 13.684 & 3 & 4.561 & 0.464 & 0.708 \\ \text { ERROR } & 540.120 & 55 & 9.820 & & \end{array}$

WITHIN SUBJECTS

$\begin{array}{lllllllll}\text { SOURCE } & S S & \text { DF } & \text { MS } & F & P & \text { G-G } & \text { H-F }\end{array}$ $\begin{array}{llllllll}\text { a } & 2.744 & 6 & 0.457 & 3.198 & 0.005 & 0.049 & 0.045\end{array}$ $\begin{array}{llllllll}\text { a*HEART } & 3.279 & 18 & 0.182 & 1.274 & 0.202 & 0.278 & 0.275\end{array}$ ERROR $\begin{array}{lll}47.183 & 330 & 0.143\end{array}$

GREENHOUSE-GEISSER EPSILON: $\quad 0.3066$

HUYNH-FELDT EPSILON : 0.3340 
Table 6a. Lactate Dehydrogenase Activity in Coronary Effluent (U/minute $x \mathrm{~g}$ dry heart weight)

Untreated Group

Time Point

$\begin{array}{lllllllllll}\text { Heart \# } & \underline{0} & \underline{5} & \underline{9} & \underline{46} & \underline{47} & \underline{48} & \underline{49} & \underline{50} & \underline{52} & \underline{55}\end{array}$

\begin{tabular}{|c|c|c|c|c|c|c|c|c|c|c|}
\hline 1 & 0.273 & 0.149 & 0.160 & 0.940 & 0.777 & 1.192 & 1.390 & 1.441 & 1.442 & 1.303 \\
\hline 2 & 0.382 & 0.895 & 0.790 & 1.547 & 1.179 & 1.282 & 1.145 & 0.874 & 0.613 & 0.613 \\
\hline 3 & 0.136 & 0.070 & 0.081 & 0.176 & 0.242 & 0.514 & 0.958 & 1.170 & 1.337 & 1.259 \\
\hline 4 & 0.100 & 0.195 & 0.130 & 0.228 & 0.894 & 1.768 & 2.210 & 2.195 & 2.141 & 1.733 \\
\hline 5 & 0.319 & 0.258 & 0.234 & 1.521 & 0.755 & 0.935 & 1.232 & 1.256 & 1.650 & 1.576 \\
\hline 6 & 0.266 & 0.210 & 0.154 & 0.750 & 0.979 & 1.350 & 1.420 & 1.686 & 1.432 & 1.234 \\
\hline 7 & 0.235 & 0.208 & 0.398 & 0.593 & 0.478 & 0.618 & 0.618 & 0.809 & 1.293 & 1.353 \\
\hline 8 & 0.174 & 0.188 & 0.307 & 0.726 & 0.752 & 1.068 & 1.026 & 0.436 & 0.942 & 0.743 \\
\hline 9 & 0.244 & 0.236 & 0.167 & 1.012 & 1.070 & 1.435 & 1.733 & 1.807 & 1.871 & 1.681 \\
\hline 10 & 0.354 & 0.247 & 0.276 & 0.974 & 1.296 & 1.353 & 1.408 & 1.655 & 1.713 & 1.716 \\
\hline 11 & 0.318 & 0.474 & 0.526 & 1.496 & 0.994 & 1.124 & 1.071 & 1.137 & 1.265 & 1.548 \\
\hline 12 & 0.441 & 0.637 & 0.201 & 1.217 & 0.786 & 1.034 & 0.952 & 0.952 & 0.880 & 0.839 \\
\hline 13 & 0.275 & 0.295 & 0.679 & 2.078 & 1.616 & 1.698 & 1.660 & 1.545 & 1.654 & 1.827 \\
\hline 14 & 0.497 & 0.504 & 0.509 & 1.604 & 0.867 & 0.709 & 0.148 & 0.639 & 0.440 & 1.157 \\
\hline 15 & 0.454 & 0.433 & 0.194 & 1.021 & 1.283 & 2.113 & 2.103 & 2.042 & 2.275 & 2.729 \\
\hline 16 & 0.429 & 0.306 & 0.189 & 0.625 & 0.186 & 0.219 & 0.371 & 0.656 & 1.155 & 1.328 \\
\hline 17 & 0.084 & 0.107 & 0.071 & 0.403 & 0.744 & 1.301 & 1.120 & 1.380 & 1.362 & 1.558 \\
\hline 18 & 0.133 & 0.079 & 0.092 & 0.584 & 0.419 & 0.968 & 1.128 & 1.446 & 1.562 & 1.230 \\
\hline 19 & 0.824 & 0.437 & 0.541 & 0.585 & 0.321 & 0.451 & 0.578 & 0.486 & 0.047 & 0.154 \\
\hline 20 & 0.176 & 0.056 & 0.258 & 1.319 & 1.296 & 1.764 & 1.707 & 1.607 & 1.547 & 1.217 \\
\hline 21 & 0.402 & 0.300 & 0.198 & 0.549 & 0.296 & 0.415 & 0.517 & 0.123 & 0.599 & 0.547 \\
\hline 22 & 0.315 & 0.200 & 0.901 & 1.226 & 0.821 & 0.991 & 0.897 & 1.024 & 1.051 & 0.845 \\
\hline 23 & 0.000 & 0.000 & 0.034 & 1.712 & 0.783 & 1.190 & 1.427 & 1.538 & 1.890 & 1.631 \\
\hline 24 & 0.282 & 0.200 & 0.167 & 0.874 & 0.804 & 1.042 & 0.888 & 0.854 & 0.973 & 1.192 \\
\hline 25 & 0.307 & 0.227 & 0.216 & 0.431 & 0.586 & 0.824 & 0.733 & 0.860 & 1.305 & 1.359 \\
\hline 26 & 0.188 & 0.215 & 0.052 & 1.052 & 1.261 & 1.532 & 1.765 & 2.275 & 2.884 & 2.957 \\
\hline 27 & 0.397 & 0.391 & 0.381 & 2.017 & 1.61 & 1.663 & 1.491 & 1.231 & 0.392 & 0.729 \\
\hline 28 & 0.559 & 0.547 & 0.389 & 0.835 & 0.449 & 0.804 & 1.587 & 1.827 & 2.329 & 2.042 \\
\hline 29 & 0.183 & 0.125 & 0.109 & 0.638 & 1.269 & 2.052 & 1.877 & 2.005 & 1.632 & 1.68 \\
\hline 30 & 0.236 & 0.225 & 0.145 & 1.008 & 2.021 & 3.126 & 3.323 & 3.241 & 3.658 & 3.146 \\
\hline 31 & 0.37 & 0.603 & 0.654 & 1.402 & 0.742 & 0.963 & 1.146 & 1.299 & 1.264 & 1.269 \\
\hline 32 & 0.122 & 0.101 & 0.117 & 0.638 & 1.364 & 1.717 & 1.876 & 1.903 & 2.182 & 1.743 \\
\hline Mean & 0.296 & 0.285 & 0.291 & 0.993 & 0.904 & 1.225 & 1.297 & 1.356 & 1.462 & 1.436 \\
\hline SD & 0.162 & 0.197 & 0.226 & 0.492 & 0.434 & 0.586 & 0.623 & 0.638 & 0.734 & 0.649 \\
\hline
\end{tabular}




\begin{tabular}{|c|c|c|c|c|c|c|c|c|c|c|}
\hline \multicolumn{11}{|c|}{$\begin{array}{r}\text { Table 6b. Lactate Dehydrogenase Activ } \\
\text { (U/minute }\end{array}$} \\
\hline \multicolumn{11}{|c|}{ Methylene Blue [1.0um]-treated Group } \\
\hline \multirow[b]{2}{*}{ Heart \# } & \multicolumn{10}{|c|}{ Time Point } \\
\hline & $\underline{a}$ & $\underline{\mathbf{5}}$ & $\underline{9}$ & 46 & 47 & $\underline{48}$ & 49 & $\underline{50}$ & 52 & $\underline{55}$ \\
\hline MB1 & 0.189 & $\overline{0.150}$ & 0.167 & $0 . \overline{4} 16$ & $\overline{0.698}$ & $\overline{1.161}$ & $\overline{1.446}$ & 1.879 & $2 \overline{280}$ & $2 \overline{856}$ \\
\hline 2 & 0.213 & 0.137 & 0.066 & 0.052 & 0.022 & 0.040 & 0.067 & 0.353 & 0.413 & 0.544 \\
\hline 3 & 0.203 & 0.176 & 0.151 & 0.580 & 1.048 & 1.609 & 1.700 & 1.577 & 1.191 & 0.860 \\
\hline 4 & 0.074 & 0.049 & 0.050 & 0.914 & 0.846 & 0.753 & 0.483 & 0.531 & 0.520 & 0.777 \\
\hline 5 & 0.196 & 0.171 & 0.162 & 0.272 & 0.189 & 0.242 & 0.092 & 0.034 & 0.437 & 0.539 \\
\hline 6 & 0.283 & 0.284 & 0.280 & 1.227 & 1.137 & 1.474 & 1.621 & 1.612 & 1.925 & 1.701 \\
\hline 7 & 0.357 & 0.284 & 0.276 & 1.090 & 1.257 & 1.606 & 1.652 & 1.544 & 1.857 & 2.046 \\
\hline 8 & 0.118 & 0.092 & 0.066 & 0.381 & 0.284 & 0.159 & 0.169 & 0.292 & 0.461 & 0.144 \\
\hline 9 & 0.242 & 0.221 & 0.180 & 1.457 & 1.692 & 2.284 & 2.537 & 2.357 & 2.777 & 3.181 \\
\hline & & & & & & & & & & \\
\hline Mean & 0.208 & 0.174 & 0.155 & 0.710 & 0.797 & 1.037 & 1.085 & 1.131 & 1.318 & 1.405 \\
\hline SD & 0.058 & 0.060 & 0.064 & 0.411 & 0.443 & 0.656 & 0.784 & 0.736 & 0.793 & 0.925 \\
\hline \multicolumn{11}{|c|}{ Methylene Blue [0.1uM]-treated Group } \\
\hline \multicolumn{11}{|c|}{ Time Point } \\
\hline Heart \# & $\underline{\mathbf{0}}$ & $\underline{5}$ & $\underline{9}$ & 46 & 47 & 48 & 49 & $\underline{50}$ & 52 & $\underline{55}$ \\
\hline MB21 & $0 . \overline{107}$ & 0.079 & 0.086 & $\overline{0.869}$ & 0.489 & 0.109 & 0.057 & 0.590 & $\overline{0.668}$ & $\overline{0.537}$ \\
\hline 22 & 0.117 & 0.098 & 0.082 & 1.075 & 0.659 & 0.394 & 0.557 & 0.450 & 0.406 & 0.415 \\
\hline 23 & 0.292 & 0.133 & 0.121 & 1.157 & 0.989 & 1.211 & 1.389 & 1.560 & 1.989 & 1.819 \\
\hline 24 & 0.133 & 0.058 & 0.064 & 0.257 & 0.355 & 0.519 & 0.514 & 0.560 & 0.457 & 0.511 \\
\hline 25 & 0.322 & 0.210 & 0.294 & 0.742 & 0.759 & 0.717 & 0.860 & 0.905 & 1.577 & 2.689 \\
\hline 26 & 0.436 & 1.053 & 0.825 & 1.366 & 1.112 & 2.884 & 3.993 & 5.103 & 5.103 & 5.579 \\
\hline 27 & 0.325 & 0.234 & 0.252 & 0.543 & 0.247 & 1.129 & 1.384 & 1.469 & 1.449 & 1.542 \\
\hline 28 & 0.337 & 0.148 & 0.147 & 0.683 & 0.949 & 1.379 & 1.429 & 1.218 & 1.335 & 2.145 \\
\hline 29 & 0.363 & 0.244 & 0.217 & 1.107 & 0.555 & 0.672 & 0.965 & 1.216 & 1.130 & 2.260 \\
\hline Mean & 0.270 & 0.251 & 0.232 & 0.867 & 0.679 & 1.002 & 1.239 & 1.452 & 1.568 & 1.944 \\
\hline SD & 0.101 & 0.178 & 0.150 & 0.276 & 0.243 & 0.577 & 0.720 & 0.839 & 0.881 & 1.088 \\
\hline \multicolumn{11}{|c|}{ Methylene Blue [10.0uM]-treated Group } \\
\hline \multicolumn{11}{|c|}{ Time Point } \\
\hline Heart \# & $\underline{\mathbf{0}}$ & $\underline{\mathbf{5}}$ & $\underline{9}$ & 46 & 47 & 48 & 49 & 50 & $\underline{52}$ & $\underline{55}$ \\
\hline MB31 & $0 . \overline{541}$ & $0 . \overline{820}$ & $0 . \overline{315}$ & $\overline{1.048}$ & $\overline{0.985}$ & 0.938 & $\overline{1.052}$ & $\overline{1.125}$ & $\overline{1.615}$ & $\overline{1.693}$ \\
\hline 32 & 0.209 & 0.379 & 0.232 & 0.425 & 0.945 & 1.715 & 1.048 & 2.180 & 1.786 & 1.661 \\
\hline 33 & 0.131 & 0.138 & 0.127 & 0.530 & 0.684 & 0.427 & 1.177 & 1.197 & 0.985 & 0.927 \\
\hline 34 & 0.260 & 0.155 & 0.065 & 0.466 & 0.600 & 0.321 & 0.069 & 0.070 & 0.405 & 0.680 \\
\hline 35 & 0.272 & 0.157 & 0.169 & 1.295 & 1.501 & 2.230 & 2.118 & 2.261 & 2.706 & 2.855 \\
\hline 36 & 0.338 & 0.278 & 0.285 & 0.991 & 1.563 & 2.342 & 2.553 & 2.813 & 2.624 & 2.462 \\
\hline 37 & 0.182 & 0.165 & 0.130 & 0.310 & 0.504 & 0.966 & 0.912 & 1.341 & 1.234 & 1.505 \\
\hline 38 & 0.156 & 0.257 & 0.487 & 0.678 & 0.530 & 0.673 & 0.645 & 0.678 & 0.551 & 0.592 \\
\hline 39 & 0.227 & 0.088 & 0.203 & 0.190 & 0.494 & 0.647 & 0.986 & 0.791 & 1.077 & 0.059 \\
\hline & & & & & & & & & & \\
\hline Mean & 0.257 & 0.271 & 0.224 & 0.659 & 0.867 & 1.140 & 1.173 & 1.384 & 1.443 & 1.382 \\
\hline SD & 0.085 & 0.148 & 0.094 & 0.306 & 0.339 & 0.637 & 0.517 & 0.689 & 0.658 & 0.726 \\
\hline
\end{tabular}


Statistical Analysis of Lactate Dehydrogenase Activity in Coronary Effluent

LEVELS ENCOUNTERED DURING PROCESSING ARE:

$$
\begin{array}{ll}
\frac{\text { HEART }}{1.000} & \text { Untreated } \\
2.000 & 0.1 \mathrm{UM} \mathrm{MB} \\
3.000 & 1.0 \mathrm{MM} \mathrm{MB} \\
4.000 & 10.0 \mathrm{MM} \mathrm{MB}
\end{array}
$$

NUMBER OF CASES PROCESSED: $\quad 59$

DEPENDENT VARIABLE MEANS

$\begin{array}{ccccccc}\text { T46 } & \text { T47 } & \text { T48 } & \text { T49 } & \text { T50 } & \text { T52 } & \text { T55 } \\ 0.880 & 0.848 & 1.149 & 1.237 & 1.341 & 1.453 & 1.500\end{array}$

LEAST SQUARES MEANS.

\begin{tabular}{lccccccc} 
HEART & $=$ & 1.000 & \multicolumn{2}{c}{$\mathrm{N}$ OF } & CASES & \multicolumn{2}{c}{32.000} \\
& $\mathrm{~T} 46$ & T47 & T48 & T49 & T50 & T52 & T55 \\
LS. MEAN & 0.993 & 0.904 & 1.225 & 1.297 & 1.356 & 1.462 & 1.436 \\
SE & 0.081 & 0.077 & .120 & 0.137 & 0.152 & 0.160 & 0.168
\end{tabular}

\begin{tabular}{lccccccc} 
HEART & 2.000 & \multicolumn{2}{c}{ N OF CASES $=$} & \multicolumn{2}{c}{9.000} & & \\
& T46 & T47 & T48 & T49 & T50 & T52 & T55 \\
LS. MEAN & 0.867 & 0.679 & 1.002 & 1.239 & 1.452 & 1.568 & 1.944 \\
SE & 0.152 & 0.145 & 0.227 & 0.259 & 0.286 & 0.302 & 0.317
\end{tabular}

$\begin{array}{lccccccc}\text { HEART }= & 3.000 \mathrm{~N} \text { OF CASES }= & 9.000 & & & \\ & \text { T46 } & \text { T47 } & \text { T48 } & \text { T49 } & \text { T50 } & \text { T52 } & \text { T55 } \\ \text { LS. MEAN } & 0.710 & 0.797 & 1.036 & 1.085 & 1.131 & 1.318 & 1.405 \\ \text { SE } & 0.152 & 0.145 & 0.227 & 0.259 & 0.286 & 0.302 & 0.317\end{array}$

HEART $=4.000 \mathrm{~N}$ OF CASES $=9.000$

$\begin{array}{lccccccc} & \text { T46 } & \text { T47 } & \text { T48 } & \text { T49 } & \text { T50 } & \text { T52 } & \text { T55 } \\ \text { LS. MEAN } & 0.659 & 0.867 & 1.140 & 1.173 & 1.384 & 1.443 & 1.382 \\ \text { SE } & 0.152 & 0.145 & 0.227 & 0.259 & 0.286 & 0.302 & 0.317\end{array}$




\section{UNIVARIATE AND MULTIVARIATE REPEATED MEASURES ANALYSIS}

\section{BETWEEN SUBJECTS}

\begin{tabular}{lccccc}
\hline SOURCE & SS & DF & MS & $F$ & $P$ \\
HEART & 1.741 & 3 & 0.580 & 0.203 & 0.894 \\
ERROR & 157.041 & 55 & 2.855 & &
\end{tabular}

WITHIN SUBJECTS

$\begin{array}{llllllllll}\text { SOURCE } & S S & \text { DF } & \text { MS } & F & P & \text { G-G } & H-F\end{array}$

$\begin{array}{lrccrrrr}\text { a } & 22.212 & 6 & 3.702 & 20.775 & 0.000 & 0.000 & 0.000 \\ \text { a*HEART } & 3.545 & 18 & 0.197 & 1.105 & 0.345 & 0.364 & 0.364 \\ \text { ERROR } & 58.804 & 330 & 0.178 & & & & \end{array}$

GREENHOUSE-GEISSER EPSILON: $\quad 0.3222$

HUYNH-FELDT EPSILON : 0.3519 
Table 7. Summary of Results with EHNA [100nM] as Treatment

\begin{tabular}{|c|c|c|c|c|}
\hline Heart \# & $(10-$ Vfib Duration)/10 & LVPP $_{\mathrm{f}} /$ LVPP $_{\mathrm{i}}$ & $\underline{H R_{f} / H R_{i}}$ & $\underline{I}$ \\
\hline E1 & .467 & .1212 & 0 & 1961 \\
\hline E2 & 1.0 & .2927 & 0.8491 & .7139 \\
\hline E3 & 0 & .0526 & 0 & .0175 \\
\hline E4 & 0 & .0278 & 0 & .0093 \\
\hline E5 & 0 & .0216 & 0 & .0072 \\
\hline E6 & .1250 & .0270 & 0 & .0507 \\
\hline E7 & 0 & .0500 & 0 & .0167 \\
\hline E8 & 0 & 0 & 0 & 0.000 \\
\hline E9 & 0 & .0512 & 0 & .0171 \\
\hline E10 & 0 & 0 & 0 & 0.000 \\
\hline E11 & 0 & .1143 & 0 & .0381 \\
\hline
\end{tabular}

Calculated Index of Recovery (Ir): .0970 .2121

Duration of Ventricular Fibrillation: $8.55 \pm 3.17$ minutes

Incidence of Ventricular Fibrillation: $90.9 \%$ 


\section{BIBLIOGRAPHY}

Ambrosio, G., Villari, B., Chiariello, M. (1992). Calcium antagonists and experimental myocardial ischemia reperfusion injury. Journal of Cardiovascular Pharmacology, 20(Suppl. 7), 826-829.

Bergmeyer, H. U. (Ed.). (1983). Methods of Enzymatic Analysis (Volume 3). Weinheim: Verlag Chemie.

Bolli, R. (1991). Oxygen-derived free radicals and myocardial reperfusion injury: an overview. Cardiovascular Drugs and Therapy, 5, 249-268.

Buege, J., Aust, S. (1978). Microsomal lipid peroxidation. Methods in Enzymology, 52, 302-310.

Christe, M. (1994). Diabetes, hypertension, and cardiac dysfunction: the role of altered hemodynamics and energy metabolism. Doctoral dissertation, University of Rhode Island.

Coudray, C., Pucheu, S., Boucher, F., deLeiris, J., Favier, A. (1992). Ischemia and reperfusion injury in isolated rat heart: Effect of reperfusion duration on xanthine oxidase, lipid peroxidation, and enzyme antioxidant systems in myocardium. Basic Research in Cardiology, 87, 478-88.

Damerau, W., Ibel, J., Thurich, T., Assadnazari, H., Zimmer, G. (1993). Generation of free radicals in Langendorff and working hearts during normoxia, hypoxia, and reoxygenation. Basic Research in Cardiology, 88, $141-149$

Darley-Usmar, V., Stone, D., Smith, D., Martin, J. (1991). Mitochondria, oxygen and reperfusion damage. Annals of Medicine, 23, 583-588.

DiSanto, A., Wagner, J. (1972). Pharmacokinetics of highly ionized drugs I: methylene blue--whole blood, urine, and tissue assays. Journal of Pharmaceutical Science, 61(4), 598-601.

DiSanto, A., Wagner, J. (1972). Pharmacokinetics of highly ionized drugs III: methylene blue--blood levels in the dog and tissue levels in the rat following intravenous administration. Journal of Pharmaceutical Science, 61(7), 1090-1094.

Downey, J. M. (1990). Free radicals and their involvement during long-term myocardial ischemia and reperfusion. Annual Review of Physiology, 52, 487-504.

Downey, J., Hearse, D., Yellon, D. (1988). The role of xanthine oxidase during 
myocardial ischemia in several species including man. Journal of Molecular and Cellular Cardiology, 20(Suppl. II), 55-63.

Ferrari, R. (1992). Importance of oxygen free radicals during ischemia and reperfusion in the experimental and clinical setting. The American Journal of Cardiovascular Pathology, 4(2), 103-114.

Ferrari, R., Ceconi, C., Curello, S., Cargnoni, A., Pasini, E., Visioli, O. (1991). The occurrence of oxidative stress during reperfusion in experimental animals and men. Cardiovascular Drugs and Therapy, 5, 277-288.

Ferrari, R., Ceconi, C., Curello, S., Cargnoni, A., Alfieri, O., Pardini, A., Marzollo, P., Visioli, O. (1991). Oxygen free radicals and myocardial damage: protective role of thiol-containing agents. The American Journal of Medicine, 91(Suppl. 3C), 95S-105S.

Flitter, W. D. (1993). Free radicals and myocardial reperfusion injury. British Medical Bulletin, 49(3), 545-555.

Gauduel, Y., Duvelleroy. (1984). Role of oxygen radicals in cardiac injury due to reoxygenation. Journal of Molecular and Cellular Cardiology, 16, 459470 .

Goldhaber, J. I., Weiss, J. N. (1992). Oxygen free radicals and cardiac reperfusion abnormalities. Hypertension, 20, 118-127.

Harper, I. S., Bond, J. M., Chacon, E., Reece, J. M., Herman, B., Lemasters, J. J. (1993). Inhibition of $\mathrm{Na}^{+} / \mathrm{H}^{+}$exchange preserves viability, restores mechanical function, and prevents the $\mathrm{pH}$ paradox in reperfusion injury to rat neonatal myocytes. Basic Research in Cardiology, 88, 430-442.

Hearse, D. J. (1991). Reperfusion-induced injury: a possible role for oxidant stress and its manipulation. Cardiovascular Drugs and Therapy, 5, 225236.

Hegstad, A. C., Ytrehus, K., Myklebust, R., Jorgensen, L. (1994). Ultrastructural changes in the myocardial myocytic mitochondria: crucial step in the development of oxygen radical-induced damage in isolated rat hearts. Basic Research in Cardiology, 89, 128-138.

Hrushesky, W., Olshefski, R., Wood, P., Meshnick, S., Eaton, J. (1985). Modifying intracellular redox balance: an approach to improving therapeutic index. The Lancet, 1(8428), 565-567.

Jennings, R. B., Reimer, K. A. (1991). The cell biology of acute myocardial 
ischemia. Annual Review of Medicine, 42, 225-246.

Karmazyn, M. (1991). Ischemic and reperfusion injury in the heart. Cellular mechanisms and pharmacological interventions. Canadian Journal of Physiological Pharmacology, 69, 719-730.

Katz, A. (1992). Physiology of the Heart (2nd ed.). New York: Raven Press.

Kehrer, J., Piper, H., Sies, H. (1987). Xanthine oxidase is not responsible for reoxygenation injury in isolated-perfused rat heart. Free Radicals in Research Communications, 3(1-5), 69-78.

Keith, F. (1993). Oxygen free radicals in cardiac transplantation. Journal of Cardiovascular Surgery, 8(Suppl), 245-248.

Kelner, M., Alexander, N. (1985). Methylene blue directly oxidizes glutathione without the intermediate formation of hydrogen peroxide. Journal of Biological Chemistry, 260(28), 15168-15171.

Kelner, M., Bagnell, R., Hale, B., Alexander, N. (1988). Potential of methylene blue to block oxygen radical generation in reperfusion injury. Basic Life Sciences, 49, 895-898.

Kelner, M., Bagnell, R., Hale, B., Alexander, N. (1988). Methylene blue competes with paraquat for reduction by flavo-enzymes resulting in decreased superoxide production in the presence of heme proteins. Archives of Biochemistry and Biophysics, 262(2), 422-426.

Korthuis, R. J., Granger, D. N. (1993). Reactive oxygen metabolites, neutrophils, and the pathogenesis of ischemic tissue/reperfusion. Clinical Cardiology, 16. $119-126$

Kukreja, R.C., Hess, M. L. (1992). The oxygen free radical system: from equations through membrane-protein interactions to cardiovascular injury and protection. Cardiovascular Research, 26, 1-14.

Mahoney, J. R. (1990). Recovery of postischemic myocardial ATP levels and hexosemonophosphate shunt activity. Medical Hypotheses, 31, 21-23.

Maupoil, V., Rochette, L., Tabard, A., Clauser, P., Harpey, C.(1990). Evolution of free radical formation during low-flow ischemia and reperfusion in isolated rat heart. Cardiovascular Drugs and Therapy, 4, 791-796.

Jeroudi, M. O., Hartley, C. J., Bolli, R. (1994). Myocardial reperfusion injury: role of oxygen radicals and potential therapy with antioxidants. American Journal of Cardiology, 73, 2B-7B. 
Park, Y. Kanekal, S. Kehrer, J. P. (1991). Oxidative changes in hypoxic rat heart tissue. American Journal of Physiology, 260, H1395-H1405.

Pierce, G. N., Meng, H. (1992). The role of sodium-proton exchange in ischemic/reperfusion injury in the heart. The American Journal of Cardiovascular Pathology, 4(2), 91-102.

Piper, H. M., Noll, T., Siegmund, B. (1994). Mitochondrial function in the oxygen depleted and reoxygenated myocardial cell. Cardiovascular Research, 28, $1-15$.

Romaschin, A., Wilson, G., Thomas, U., Feitler, D., Tumiati, L., Mickle, D. (1990). Subcellular distribution of peroxidized lipids in myocardial reperfusion injury. American Journal of Physiology, 259, H116-H123.

Salaris, S. C., Babbs, C. F., Voorhees, W. D. (1991). Methylene blue as an inhibitor of superoxide generation by xanthine oxidase. Biochemical Pharmacology, 42(3), 499-506.

Scholz, W., Albus, U. (1993). $\mathrm{Na}^{+} / \mathrm{H}^{+}$exchange and its inhibition in cardiac ischemia and reperfusion. Basic Research in Cardiology, 88, 443-455.

Steenbergen, C., Fralix, T. A., Murphy, E. (1993). Role of increased cytosolic free calcium concentration in myocardial ischemic injury. Basic Research in Cardiology, 88, 456-470.

Tani, M. (1990). Mechanisms of calcium overload in reperfused ischemic myocardium. Annual Review of Physiology, 52, 543-549.

Tani, M., Neely, J. R. (1989). Role of intracellular $\mathrm{Na}^{+}$in $\mathrm{Ca}^{2+}$ overload and depressed recovery of ventricular function of reperfused ischemic rat hearts. Circulation Research, 65, 1045-1056.

Tavazzi, B., Cerroni, L., DiPierro, D., Lazzarino, G., Nuutinen, M., Starnes, J., Giardina, B. (1990). Oxygen radical injury and loss of high-energy compunds in anoxic and reperfused rat heart: prevention by exogenous fructose-1,6-bisphosphate. Free Radicals in Research Communications, 10(3), 167-176.

Tietz, N. W. (Ed.). (1987). Fundamentals of Clinical Chemistry (3rd ed.). Philadelphia: W. B. Saunders Co.

Vaage, J., Valen, G. (1993). Pathophysiology and mediators of ischemiareperfusion injury with special reference to cardiac surgery. Scandinavian Journal of Thoracic and Cardiovascular Surgery Supplement, 41, 1-18. 
Zhu, Q., Chen, S., Zou, C. (1990). Protective effects of an adenosine deaminase inhibitor on ischemia-reperfusion injury in isolated perfused rat heart. American Journal of Physiology, 259, H835-838. 